Article

\title{
Comparison and Sensitivity Investigations of a CALM and SALM Type Mooring System for Wave Energy Converters
}

\author{
Arthur Pecher *, Aligi Foglia and Jens Peter Kofoed
}

Department of Civil Engineering, Aalborg University, Sohngaardsholmsvej 57, Aalborg 9000, Denmark; E-Mails: afo@civil.aau.dk (A.F.); jpk@civil.aau.dk (J.P.K.)

* Author to whom correspondence should be addressed; E-Mail: afsp@civil.aau.dk; Tel.: +45-9940-8474.

Received: 16 December 2013; in revised form: 15 January 2014 / Accepted: 23 January 2014 / Published: 18 February 2014

\begin{abstract}
A quasi-static analysis and sensitivity investigation of two different mooring configurations - a single anchor leg mooring (SALM) and a three-legged catenary anchor leg system (CALM) - is presented. The analysis aims to indicate what can be expected in terms of requirements for the mooring system size and stiffness. The two mooring systems were designed for the same reference load case, corresponding to a horizontal design load at the wave energy converter (WEC) of $2000 \mathrm{kN}$ and a water depth of $30 \mathrm{~m}$. This reference scenario seems to be representative for large WECs operating in intermediate water depths, such as Weptos, Wave Dragon and many others, including reasonable design safety factors. Around this reference scenario, the main influential parameters were modified in order to investigate their impact on the specifications of the mooring system, e.g. the water depth, the horizontal design load, and a mooring design parameter.
\end{abstract}

Keywords: catenary mooring; CALM; tension leg mooring; single anchor leg mooring; SALM; wave energy converter; WEC; mooring systems; compliance mooring; mooring stiffness; QS analysis; ultimate limit state; ULS 


\section{Introduction}

The mooring system is a vital part of offshore wave energy converters (WEC) as it is responsible for the station-keeping of the WEC, but it counts as well for a significant part of the overall cost of the device [1]. Therefore, it must have a relatively low system and installation cost and be reliable, to ensure there is little downtime and long intervals between maintenance. As the installation timeframe of WECs greatly exceeds five years, they require long-term mooring installation, which is supported by the offshore standard on position mooring DNV-OS-E301 [2].

This document presents a quasi-static analysis for an ultimate limit state (I) and sensitivity investigation of two different mooring configurations, which provides a decent preliminary design of the mooring systems $[3,4]$. Although many different types of suitable mooring systems exist for wave energy converters [5], a traditional three-legged catenary anchor leg mooring (CALM) and a single anchor leg mooring (SALM) are being analyzed here. It aims to indicate what can be expected in terms of requirements for the mooring system size and stiffness. The two mooring systems were subjected to the same reference load case, in order to represent an extreme load scenario of a large floating WEC in intermediate water depths. This reference load case consists of a horizontal design load at the WEC of $2000 \mathrm{kN}$ at a water depth of $30 \mathrm{~m}$, which seems to be representative of large WECs, such as Weptos, Wave Dragon and many others, including reasonable safety factors (II). However, additional safety factors might be required, for example, for corrosion protection of catenary chains (in the case of the CALM) or the absence of redundancy (in the case of the SALM) (III). Around this reference scenario, the main influential parameters were modified in order to investigate their impact on the mooring system, e.g., the water depth, the horizontal design load at the WEC and a mooring design parameter.

(I) An ultimate limit state (ULS) corresponds to the design criteria where the individual components of the mooring system have adequate strength to withstand the maximum environmental loads [2].

(II) The design of the mooring system for wave energy converters can be performed under consequence class 1 [6]. This consequence class presents a 1.7 safety factor for the mean and dynamic tension for a ULS quasi-static analysis. To calculate the characteristic strength of a component, the minimum breaking strength is multiplied by a factor of 0.95 .

(III) In the case that a system does not provide any redundancy, the safety factor is multiplied by a factor of 1.2. Depending on the type of inspection, the corrosion allowance referring to the chain diameter of a suspended catenary chain is 0.2 or $0.3 \mathrm{~mm} / \mathrm{year}$.

The SALM system was first developed for the mooring and loading of large tankers offshore in severe environments and was first used in 1969 [7]. It consists, in this case, of a submerged mooring buoy that is anchored through a tension leg (the tether) by a suction anchor. This buoy is then connected through a hawser to the wave energy converter (WEC).

Spread moorings using catenary lines are commonly used for semi-submersible structures in shallow water. The restoring force from a catenary system comes from the suspended weight of the mooring lines, which changes in configuration with the excursion of the WEC. The mooring lines of the catenary system terminate at the seabed horizontally, which means that the anchor point is only 
subjected to horizontal forces. This results in relatively long mooring lines compared to the water depth.

\section{CALM System}

This CALM system consists of three catenary mooring lines (spaced 120 degrees apart), three anchors, an intermediate buoy, and a hawser connecting the buoy to the WEC (see Figure 1). The restoring force of the system comes from the weight and suspended length of the catenary mooring lines and from the elasticity of the hawser and catenary mooring lines. An overview of the layout of the mooring configuration is given in the next figure (Figure 1).

Figure 1. Illustration of the three-legged catenary anchor leg mooring (CALM) system configuration.
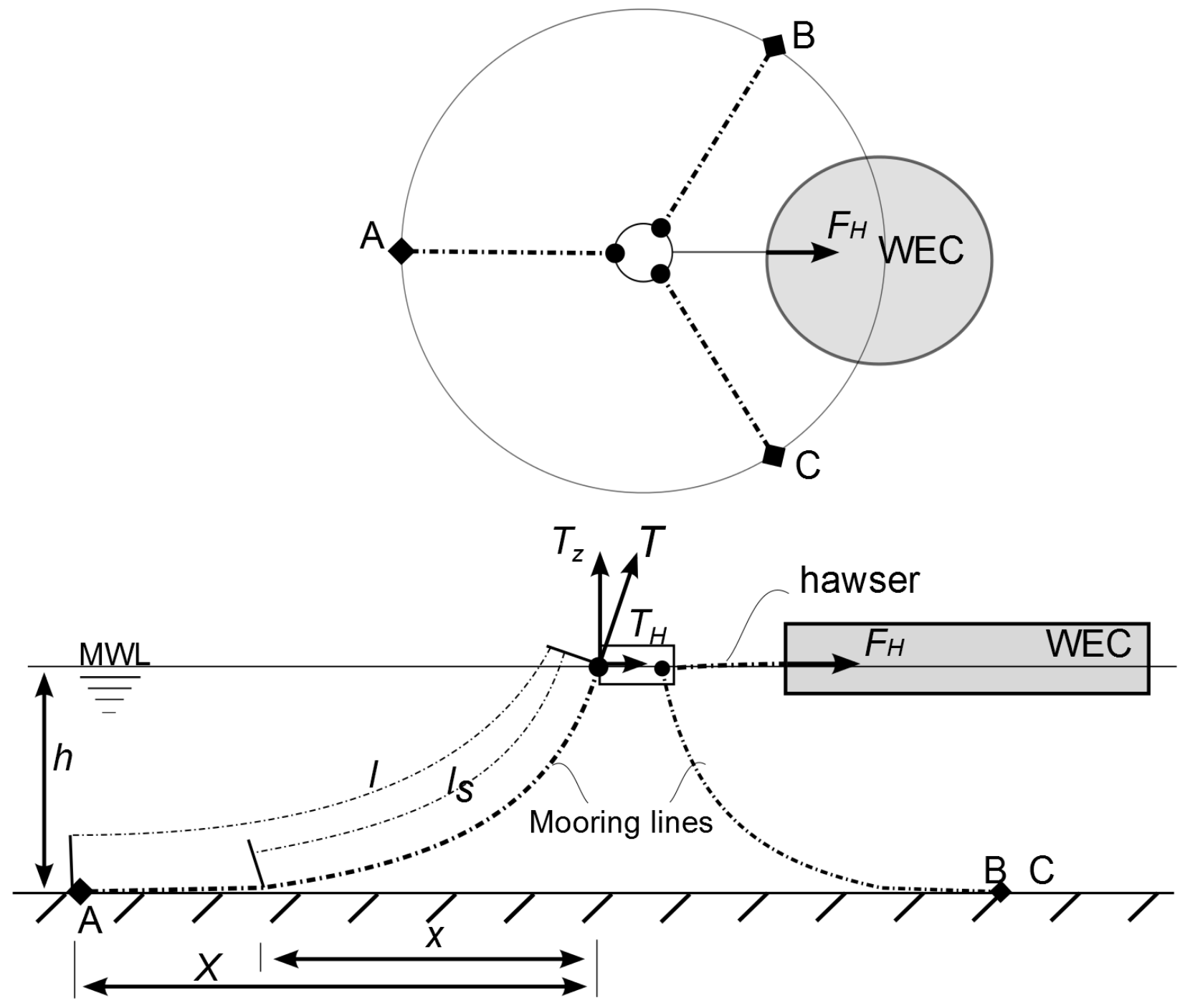
Some design criteria are respected:

- The length of the mooring lines was calculated such that the anchors are not exposed to vertical forces from the mooring lines.

- The design load of all the mooring lines is set equal to the resulting tension in them under the design conditions.

- The length of the hawser is $30 \mathrm{~m}$.

- The buoy volume was calculated so that its buoyancy force is equal to the combined force of its own weight, the vertical forces from the three mooring lines (combined $T_{v}$ ), half of the weight of the hawser and $250 \mathrm{~kg}$ for extra equipment.

- The horizontal pretension in the mooring lines was set to $20 \mathrm{kN}$, which corresponds to $1 \%$ of the maximum design load at the WEC.

The elasticity of the mooring lines is considered, while the following assumptions and approximations are made for the calculations:

- There is no back mooring line considered.

- The sea bed is horizontal.

- There is no bending mooring stiffness in the chains.

- Dynamic effects in the mooring lines are ignored.

- Current forces resulting from the movement of the chains in the water and on the seabed are ignored.

- Friction on the seabed is ignored.

- Mooring lines have a constant weight per unit length.

- The angle between the chains is assumed constant at 120 degrees (as the horizontal excursion is small relative to the length of the chains).

- The environmental loads are in line with one of the three mooring lines.

- The mooring lines are assumed to be connected to the buoy at mean water level.

The forces at the different locations and the length of the different components under different tensions, taking the elasticity of the mooring lines into account, can be derived from the following equations [8,9]. First, the horizontal design load $\left(T_{H_{\max }}\right)$ at the buoy can be found based on an assumed resultant tension and other specifications of the system.

$$
T_{H_{\max }}=A E \sqrt{\left(2 \frac{T_{\max }}{w h}+1\right)^{2}-\frac{2 w h}{A E}}-A E
$$

The minimum unstretched length of the chain $l_{\text {min, },}$ (the subscript 0 indicates that it corresponds to the unstretched value) can then be found, which is calculated relative to the necessary chain length so that the anchor will not have any vertical tension.

$$
l_{\min , 0}=\frac{1}{w} \sqrt{T_{\max }^{2}-T_{H}^{2}}
$$

From this, the maximum vertical force at the fairlead on the buoy can be found with

$$
T_{z_{\max }}=w l_{\min , 0}
$$


From here, the following steps need to be repeated to obtain the force-displacement curve. First, a value of $T_{z}$ needs to be assumed. From this, the unstretched value of $l_{s, 0}$ can be obtained through (see Figure 1)

$$
l_{s, 0}=\frac{T_{z}}{w}
$$

$T_{H}$ can then be calculated with

$$
T_{H}=\frac{T_{z}^{2}-\left(w h-\frac{1}{2} \frac{w^{2}}{A E} l_{s, 0}^{2}\right)^{2}}{2\left(w h-\frac{1}{2} \frac{w^{2}}{A E} l_{s, 0}^{2}\right)}
$$

The resultant force at the fairlead is

$$
T=\sqrt{T_{Z}^{2}-T_{H}^{2}}
$$

Based on this, the length of the hanging part of the chain can be calculated by

$$
x=\frac{T_{H}}{w} \ln \left(\frac{T+T_{Z}}{T_{H}}\right)+\frac{T_{H} l_{s, 0}}{A E}
$$

The stretched length of $l_{s}$, which is the hanging part of the chain, can then be obtained by

$$
l_{s}=\frac{T_{H}}{w} \sinh \left(\frac{w x}{T_{H}}\right)
$$

The stretched length of the lying part of the line $\left(l-l_{S}\right)$ has to be calculated with $T_{H}$ and the elasticity coefficients of the chain. $l_{\min }$ is equal to $l$, as no additional chain length is considered.

$$
l-l_{s}=\left(l_{\min , 0}-l_{s, 0}\right)\left(1+f T_{H}\right)
$$

Finally, the horizontal distance between the anchor and the buoy can be found using the stretched values of the lines with

$$
X=l-l_{s}+x
$$

The resulting distance between the buoy and the two other mooring lines can be obtained easily assuming that the angle between the lines remains at all times at 120 degrees. Thereby, the change in distance between the buoy and anchor $\mathrm{B}$ and $\mathrm{C}$ is half of the increase in distance between anchor $\mathrm{A}$ and the buoy.

\section{SALM System}

The single anchor leg mooring (SALM) system, also referred to as a tension leg mooring system, consists of an anchor point, which in this case is a suction anchor, two mooring lines (a tether and a hawser) and a submerged buoy (see Figure 2). The restoring force of the system comes from the buoyancy force of the buoy and the elasticity of the tether and hawser. 
Figure 2. Illustration of the single anchor leg mooring (SALM) system.

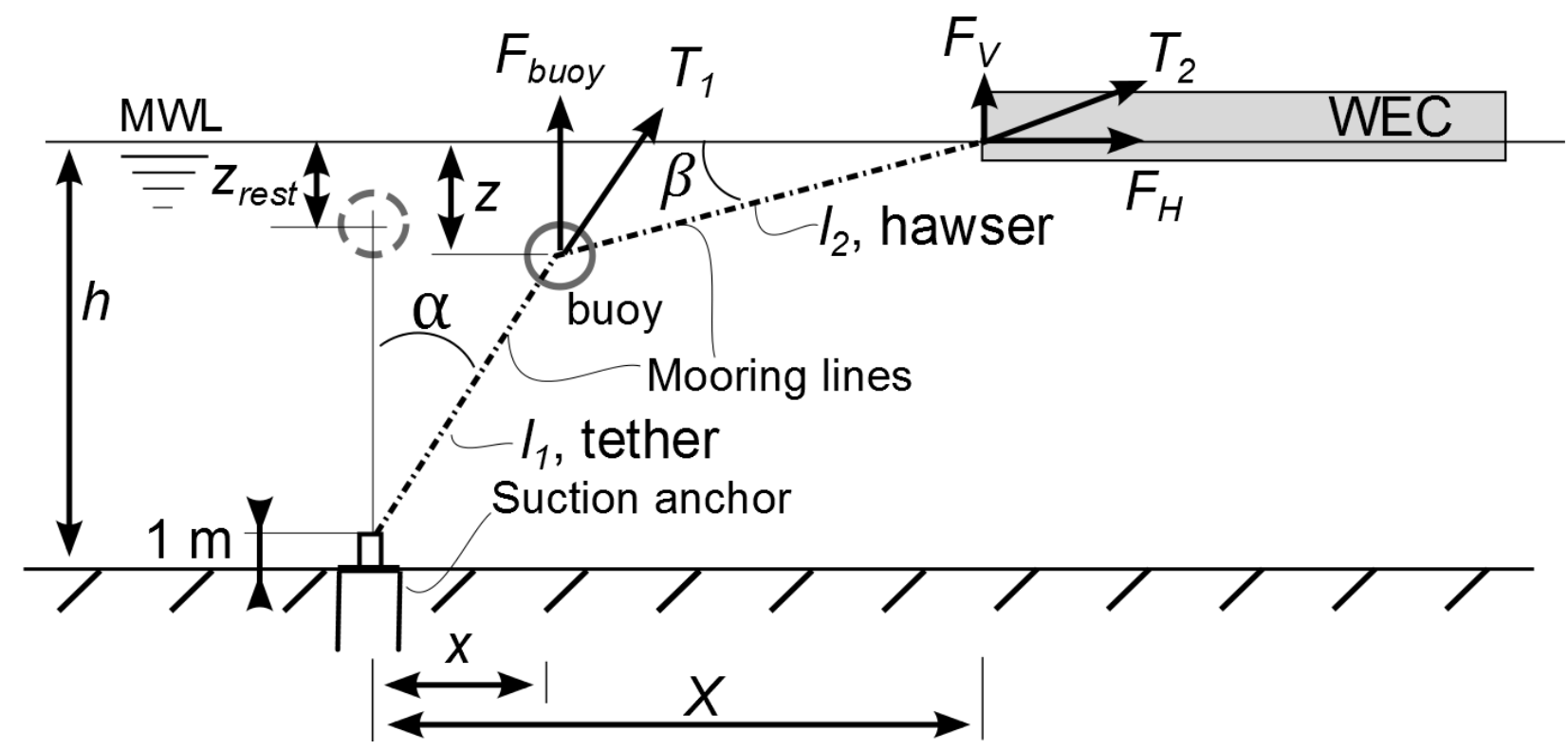

Some design criteria are respected:

- The angle between the hawser and tether at maximum excursion of the WEC is equal to 160 degrees. Although angles up to 180 degrees are physically possible, the resulting horizontal force increases too exponentially after 160 degrees (illustrated in Figure 3). This can therefore not be part of the useable range of the mooring system, and was thereby excluded.

- The design load of the lines is set equal to the maximum resulting tension in them under the design condition.

- The depth of the buoy at rest, $z_{\text {rest }}$, is calculated taking the maximum wave height into account (33\% of $1.86^{*} H_{s}$ of a hundred year storm) and half of the height of the buoy, where the buoy is assumed to be a cylinder of equal height and diameter.

- The length of the hawser is $30 \mathrm{~m}$.

- The volume of the buoy is calculated relative to the required buoyancy force to fulfill the specifications of the mooring system. The combined gravitational force of the system consists of the buoy's own weight, the weight of the tether, half of the weight of the hawser and $250 \mathrm{~kg}$ for extra equipment.

- The length of the tether is a result of the water depth, the submergence depth of the buoy at rest and the height of the connection on the seabed.

Some assumptions were taken into account:

- There is no back mooring line considered.

- Dynamic effects in the line are ignored.

- Current forces resulting from the movement of the chain in the water and on the seabed are ignored.

- The mooring line is assumed to be connected to the WEC at mean water level. 
Figure 3. Overview of the force excursion and the mooring stiffness curve, together with the maximum admissible $F_{H}$ and the extension of the force-displacement curve, given against the WEC excursion and relative angle between the tether and hawser.
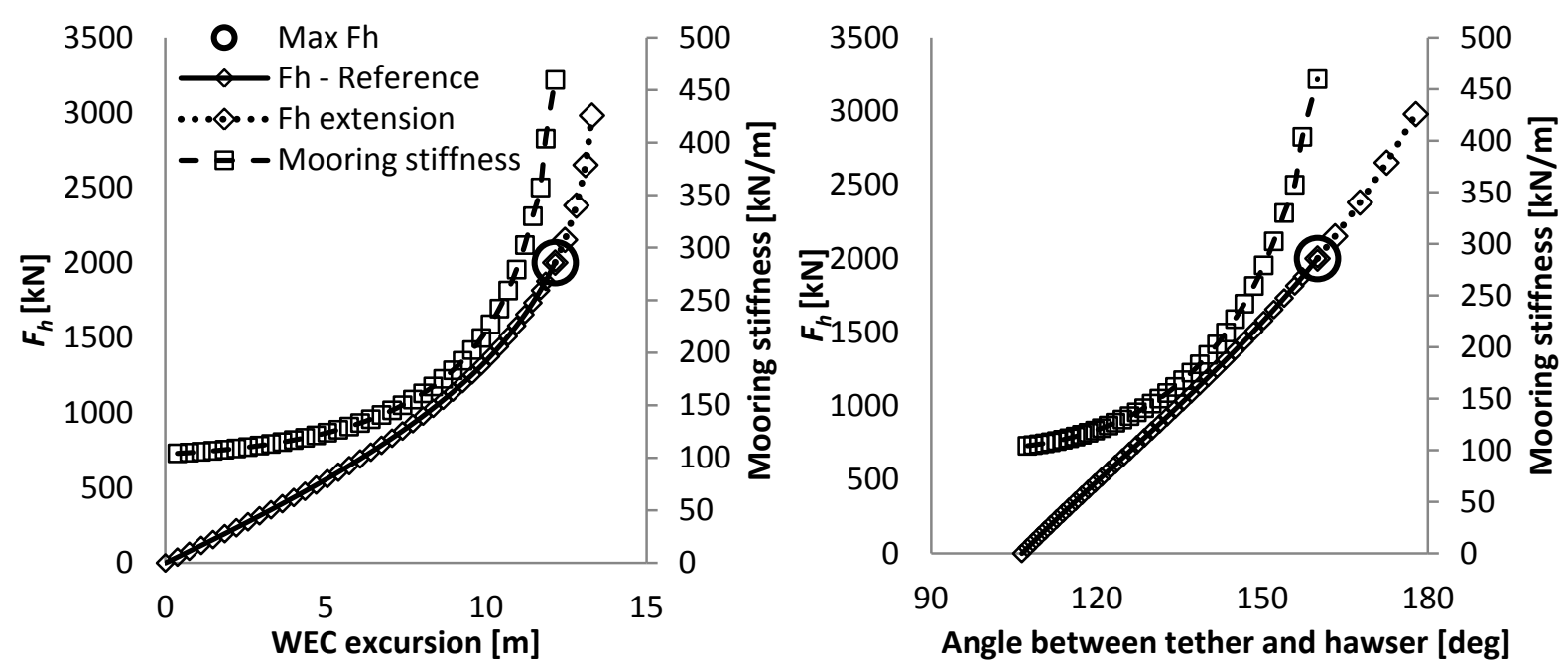

The calculations related to the SALM system can be obtained through an iteration process and the various forces and angles in the system can mainly be obtained geometrically with the equations described below.

The elongation of the lines can be calculated with their elasticity $(f)$ and the applied tension (the superscript 0 indicates that it corresponds to their unstretched lengths).

$$
\begin{gathered}
l=l^{0}(1+f T) \\
\alpha=\operatorname{asin}\left(\frac{x_{1}}{l_{1}}\right)
\end{gathered}
$$

The depth of the buoy, where $z_{\text {rest }}$ represents the depth of the buoy at rest (no load situation), is:

$$
z=z_{\text {rest }}+l_{1}-l_{1} \cos (\alpha)
$$

The force at the buoy is

$$
T_{1}=\frac{F_{b u o y}}{\cos (\alpha)}
$$

The horizontal force at the WEC is

$$
F_{H}=T_{1} \sin (\alpha)
$$

The angle between the second line and the mean water level (MWL) is

$$
\beta=\operatorname{asin}\left(\frac{Z}{l_{2}}\right)
$$

The overall tension at the WEC is

$$
T_{2}=\frac{F_{H}}{\cos (\beta)}
$$




\section{Specifications}

\subsection{Reference Load Case}

The environmental conditions and loads are chosen with the objective to be as generic as possible. Therefore, they were inspired from values that were obtained from tank testing of various large devices [10,11]. The parametric study will analyse some of the effect of these environmental conditions, around the reference load case, presented in Table 1. However, whenever a quasi-static analysis has to be performed for a device at a specific location, the corresponding environmental load should be calculated following [2], and the design should also be verified for an accidental limit state and fatigue limit state besides the "ultimate limit state" case assessed here.

Table 1. Overview of the specifications of the reference load case.

\begin{tabular}{cccc}
\hline & Unit & Symbol & Value \\
\hline Water depth & {$[\mathrm{m}]$} & $h$ & 30 \\
Horizontal design load at the WEC & {$[\mathrm{kN}]$} & $F_{\text {Hmax }}$ & 2000 \\
\hline
\end{tabular}

Note that the mooring stiffness, also called the resulting horizontal compliance, indicates the rate of change in the horizontal mooring force for a given WEC excursion (similar to the derivative of the force-displacement curve). It evolves differently with the excursion of the WEC depending on the mooring characteristics and has thereby a high influence on the horizontal design load at the WEC. As the mooring stiffness over the permissible excursion of the WEC is different for both mooring systems, the resulting horizontal design load at the WEC of a dynamic or experimental analysis can be expected to be different as well. However, the configurations that are presented are believed to be representative of what would physically be required under these specifications. A dynamic or experimental analysis should provide better indications of the WEC motions and resulting mooring forces.

The maximum values are set against a possible 100 -year storm having a $H_{s}$ value of $8.28 \mathrm{~m}$ and a $T_{p}$ of $12.9 \mathrm{~s}$ at a water depth of $30 \mathrm{~m}$, which corresponds to a maximum wave height of $15.4 \mathrm{~m} \mathrm{[12]}$ (we assume that the maximum wave trough will be one third of this, corresponding to $5.1 \mathrm{~m}$ ). With fifth order stokes waves, we obtain a maximum wave trough of $4.7 \mathrm{~m}$ in these wave conditions [13].

\subsection{Chain}

The characteristics of the chain (diameter, dry and submerged weight $w$ ) of steel grade Q3 were extra- and interpolated based on chain specifications presented in [14] and the axial mooring stiffness $(A E)$ specifications were based on [9]. The elasticity $f$ is the reciprocal of the axial mooring stiffness. These different characteristics were calculated with the following equations (in which $T_{\max }$ is in $[\mathrm{kN}]$ ):

$$
\begin{gathered}
\text { Chain nominal diameter, } D[\mathrm{~mm}]=\left(0.8063 T_{\max }\right)^{0.543449} \\
\text { Unit weight of the chain }[\mathrm{N} / \mathrm{m}]=0.3107 T_{\max }-104.4 \\
\text { Submerged weight of the chain, } w[\mathrm{~N} / \mathrm{m}]=0.2665 T_{\max }-76.105 \\
\text { Axial stiffness per unit length, } A E[N]=90000 D^{2}
\end{gathered}
$$




\subsection{Wire Rope}

The characteristics of the six strand wire rope IWRC (diameter, dry and submerged weight $w$ and the elasticity), having an ultimate tensile stress of $1770 \mathrm{~N} / \mathrm{mm}^{2}$, were extra- and interpolated based on chain specifications presented in $[9,14]$. The wire rope specifications, used as a hawser for the catenary solution, could possibly be improved by lowering their mooring stiffness below the overall mooring stiffness (mooring stiffness at maximum WEC excursion) of the mooring system, possibly by using a fibre rope solution.

$$
\begin{gathered}
\text { Wire rope nominal diameter }[\mathrm{mm}]=\left(\frac{T_{\max }}{525}\right)^{\frac{1}{2}} \\
\text { Unit weight of the wire rope }[\mathrm{N} / \mathrm{m}]=0.0653 T_{\max }-0.585 \\
\text { Submerged weight of the wire rope } w[N / m]=0.0574 T_{\max }-2.1084 \\
\text { Elasticity, } f\left[N^{-1}\right]=-5.5026 E^{-19} T_{\max }{ }^{3}+4.1023 E^{-15} T_{\max }{ }^{2} \\
-1.0244 E^{-11} T_{\max }+1.2774 E^{-18}
\end{gathered}
$$

\subsection{Flipper-Delta Anchor}

In this exercise, for the spread catenary mooring system Flipper-Delta anchors were selected. The holding capacity of the anchor is set equal to the horizontal design load at the WEC and its weight can be calculated with the following equation for a range of anchor weights between 0.3 and 27.5 ton (3 and $270 \mathrm{kN}$ ) [14]:

$$
W=\left(\frac{F_{H_{\text {max }}}}{K_{\text {mean }}}\right)^{\frac{1}{\delta}}
$$

where:

- $W$ is the weight of the anchor [kN].

- $K_{\text {mean }}$ and $\delta$ are the fitting coefficient, 42 and 0.85 .

- $F_{\text {Hmax }}$ is the horizontal design load at the WEC [kN].

It was chosen to use $K_{\text {mean }}$, which is the average value between the maximum and minimum value of $K$ (28 and 58), as this depends on the soil. The safety factors are assumed to be taken into account in the horizontal design load at the WEC.

\subsection{Suction Anchor}

Suction anchors have been used to moor buoyant oil and gas facilities for the last 40 years [15]. In this section, the procedure for the preliminary design of a suction anchor for the SALM system is described. The design is preliminary in the sense that it is merely based on a geotechnical analysis. The following hypotheses are necessary to the preliminary design:

- A mono-layer soil profile is assumed. The soil is medium soft clay with homogeneous strength profile, average undrained shear strength, $s_{u}=35 \mathrm{kPa}$, and saturated unit weight, 
$\gamma_{\text {sat }}=19 \mathrm{kN} / \mathrm{m}^{3}$. This is selected accordingly to what is likely to be found in the Danish sector of the North Sea.

- The mooring is connected to the suction anchor by means of a padeye placed on the foundation lid. The thickness of lid and wall of the anchor was chosen by taking existing similar foundations as reference.

The force calculated at the buoy, $T_{1}$, implies vertical and horizontal components acting on the foundation, $V$ and $H$, respectively. Note that $V$ exerts constant uplift on the anchor. The uplift vertical capacity $V_{u l t}$ and the horizontal capacity $H_{u l t}$ of the suction anchor are calculated following [16]. The foundation failure model taken as reference to calculate $V_{u l t}$ includes three contributions: the caisson weight, the external wall friction, and the soil plug:

$$
V_{u l t}=W^{\prime}+A_{s e} \alpha_{e} s_{u}+W_{p l u g}^{\prime}
$$

where:

- $W^{\prime}$ and $W_{\text {plug }}^{\prime}$ are the buoyant weight of the foundation and of the soil plug

- $A_{s e}$ is the external shaft surface area

- $\alpha_{e}$ is the external adhesion factor, assumed equal to 0.5

- $s_{u}$ is the undrained shear strength of the soil.

It is worth noting that in the calculation of $V_{u l t}$, the reverse end bearing capacity is assumed to be not relevant since the foundation is subjected to sustained vertical load.

$H_{\text {ult }}$ is calculated as:

$$
H_{u l t}=d D_{e} N_{p} s_{u}
$$

where:

- $d$ is the anchor length.

- $D_{e}$ is the external diameter.

- $N_{p}$ is the lateral bearing capacity factor that depends on the embedment ratio $d / D_{e}$ and on where the padeye is located. Since the padeye is placed on the lid, $N_{p}$ was set equal to 3 .

Since $H$ and $V$ are simultaneously applied to the foundation, overlooking their interaction would be non-conservative. The interaction diagram proposed by [17] was used to complete the analysis:

$$
\left(\frac{H}{H_{u l t}}\right)^{a}+\left(\frac{V}{V_{u l t}}\right)^{b}=1
$$

where $a$ and $b$ are the parameters of the interaction diagram which depend on the embedment ratio.

Seven different sizes of suction anchor were designed to fulfill the seven different loading cases. The dimensions of the suction anchors, including the thickness of lid and wall, are listed in annexed Tables 2-4. In Figure 4, the failure envelope obtained with Equations 27-29 is plotted together with the reference loading conditions calculated for the reference SALM system. 
Figure 4. Failure envelope of the suction anchor encompassing the reference design load point.

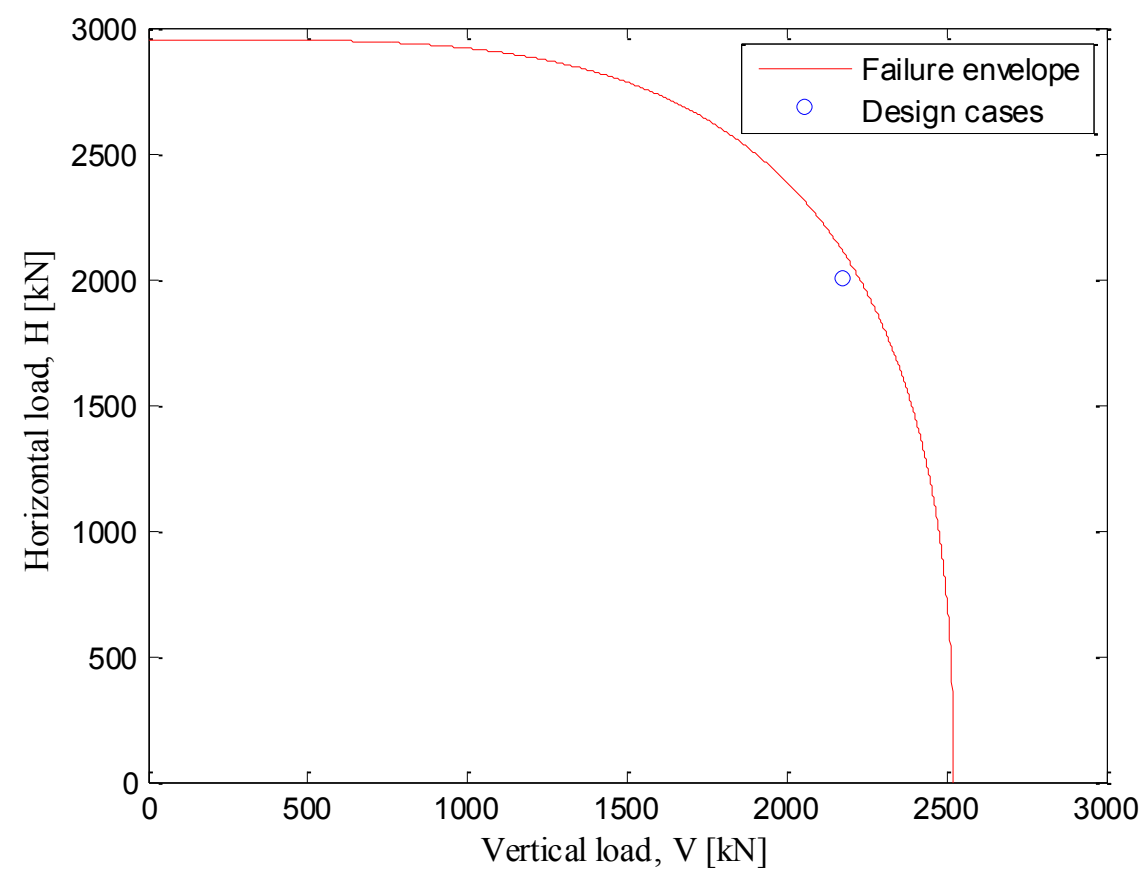

Table 2. Main results from investigating the influence of the length of the hawser, $l_{2}$, of the SALM system.

\begin{tabular}{cccc}
\hline & $\boldsymbol{l}_{\mathbf{2 , 0}} \mathbf{- 3 3 \%}$ & Reference & $\boldsymbol{l}_{\mathbf{2 , 0}}+\mathbf{3 3 \%}$ \\
\hline length $l_{2,0}[\mathrm{~m}]$ & 20 & 30 & 40 \\
Max excursion $[\mathrm{m}]$ & 9.3 & 12.1 & 13.8 \\
Mooring stiffness at max excursion $[\mathrm{kN} / \mathrm{m}]$ & 465 & 460 & 469 \\
alpha $\left[^{\circ}\right]$ & 33 & 42.6 & 47.9 \\
Beta $\left.{ }^{\circ}\right]$ & 37.0 & 27.4 & 22.1 \\
Buoy volume $\left[\mathrm{m}^{3}\right]$ & 350 & 248 & 206 \\
Equivalent to a cylinder of height and diameter $[\mathrm{m}]$ & 7.6 & 6.8 & 6.4 \\
Length $l_{1,0}[\mathrm{~m}]$ & 20.1 & 20.5 & 20.7 \\
$F_{\text {buoy }}[\mathrm{kN}]$ & 3086 & 2178 & 1808 \\
Max $T_{1}[\mathrm{kN}]$ & 3677 & 2957 & 2696 \\
Max $T_{2}[\mathrm{kN}]$ & 2505 & 2254 & 2159 \\
Suction anchor diameter $[\mathrm{m}]$ & 4.25 & 3.75 & 3.55 \\
Suction anchor height $[\mathrm{m}]$ & 8.5 & 7.5 & 7.1 \\
Suction anchor lid thickness $[\mathrm{mm}]$ & 100 & 100 & 100 \\
Suction anchor wall thickness $[\mathrm{mm}]$ & 30 & 26 & 25 \\
Suction anchor weight [ton] & 37 & 27 & 23 \\
Total weight $[$ ton] & 82 & 59 & 50 \\
\hline
\end{tabular}


Table 3. Main results from investigating the influence of water depth on a SALM system.

\begin{tabular}{cccc}
\hline & Water depth - 33\% & Reference & Water depth + 33\% \\
\hline Water depth $[\mathrm{m}]$ & 20 & 30 & 40 \\
Max excursion $[\mathrm{m}]$ & & 12.1 & 16.7 \\
Alpha $\left[^{\circ}\right]$ & 7.0 & 460 & 310 \\
Beta $\left.{ }^{\circ}{ }^{\circ}\right]$ & 879 & 42.6 & 39.2 \\
Mooring stiffness at max excursion $[\mathrm{kN} / \mathrm{m}]$ & 47.1 & 27.4 & 279.4 \\
Buoy volume $\left[\mathrm{m}^{3}\right]$ & 22.9 & 247.6 & 7.1 \\
Equivalent to a cylinder of height and diameter $[\mathrm{m}]$ & 210.85 & 6.8 & 30.4 \\
Length $l_{l, 0}[\mathrm{~m}]$ & 6.5 & 20.5 & 2457 \\
$F_{\text {buoy }}[\mathrm{kN}]$ & 10.7 & 2178 & 3168 \\
Max $T_{l}[\mathrm{kN}]$ & 1856 & 2957 & 2330 \\
Max $T_{2}[\mathrm{kN}]$ & 2728 & 2254 & 3.9 \\
Suction anchor diameter $[\mathrm{m}]$ & 2171 & 3.75 & 7.8 \\
Suction anchor height $[\mathrm{m}]$ & 3.6 & 7.5 & 100 \\
Suction anchor lid thickness $[\mathrm{mm}]$ & 7.2 & 100 & 27 \\
Suction anchor wall thickness $[\mathrm{mm}]$ & 100 & 26 & 30 \\
Suction anchor weight $[$ ton] & 25 & 27 & 66
\end{tabular}

Table 4. Main results from investigating the influence of horizontal design load at the WEC on a SALM system.

\begin{tabular}{|c|c|c|c|}
\hline & $-50 \% F_{h \max }$ & Reference & $+50 \% F_{h \max }$ \\
\hline Horizontal design load $F_{h \max }[\mathrm{m}]$ & 1000 & 2000 & 3000 \\
\hline Max excursion $[\mathrm{m}]$ & 12.6 & 12.1 & 11.7 \\
\hline Mooring stiffness at max excursion $[\mathrm{kN} / \mathrm{m}]$ & 231 & 460 & 703 \\
\hline Alpha $\left[^{\circ}\right]$ & 43.2 & 42.6 & 42.2 \\
\hline $\operatorname{Beta}\left[{ }^{\circ}\right]$ & 26.7 & 27.4 & 27.8 \\
\hline Buoy volume $\left[\mathrm{m}^{3}\right]$ & 121 & 248 & 376 \\
\hline Equivalent to a cylinder of height and diameter [m] & 5.4 & 6.8 & 7.8 \\
\hline Length $l_{1,0}[\mathrm{~m}]$ & 21.2 & 20.5 & 20.0 \\
\hline$F_{\text {buoy }}[\mathrm{kN}]$ & 1063 & 2178 & 3308 \\
\hline $\operatorname{Max} T_{1}[\mathrm{kN}]$ & 1459 & 2957 & 4466 \\
\hline $\operatorname{Max} T_{2}[\mathrm{kN}]$ & 1119 & 2254 & 3393 \\
\hline Suction anchor diameter $[\mathrm{m}]$ & 2.75 & 3.75 & 4.5 \\
\hline Suction anchor height $[\mathrm{m}]$ & 5.5 & 7.5 & 9 \\
\hline Suction anchor lid thickness [mm] & 100 & 100 & 100 \\
\hline Suction anchor wall thickness $[\mathrm{mm}]$ & 19 & 26 & 31 \\
\hline Suction anchor weight [ton] & 12 & 27 & 44 \\
\hline Total weight [ton] & 28 & 59 & 92 \\
\hline
\end{tabular}




\subsection{Bиоу}

The buoys are assumed to have a weight density of $125 \mathrm{~kg} / \mathrm{m}^{3}$ and to be of equal height as diameter. The volume of the buoy is calculated to provide the required buoyancy force, which is described in the section of the CALM and SALM systems.

\section{Results and Discussion}

\subsection{CALM-Sensitivity Investigation}

\subsubsection{Reference Load Case}

Based on the specifications of the mooring system, the dimensioning of the components has been made by mainly following $[9,14]$. The following figure (Figure 5) presents the force-displacement curves for the different lines and for the whole mooring system, together with the resulting stiffness of the mooring relative to the WEC excursion.

Figure 5. Overview of the forces in the CALM system and in its individual lines together with the mooring stiffness of the mooring system.



It can be seen that most of the compliance comes from the catenary mooring lines, as in this case, the hawser had a very low elasticity. The resulting force-displacement curve of the "active" mooring line is almost identical to the overall force-displacement curve, meaning that the other mooring lines have very little influence on the system. All the related values and details of the mooring configuration can be found in Table 5 . 
Table 5. Summary of the main details of the spread catenary mooring system for the reference load case.

\begin{tabular}{|c|c|c|c|c|}
\hline & & Unit & Symbol & Value \\
\hline & Pre-tension & {$[\mathrm{kN}]$} & & 20 \\
\hline \multirow[t]{8}{*}{ Chain } & Steel grade Q3 & & & \\
\hline & Unstretched length & {$[\mathrm{m}]$} & $l_{\min , 0}$ & 509 \\
\hline & Minimum breaking force * & {$[\mathrm{kN}]$} & $T_{\max }$ & 2014 \\
\hline & Diameter & {$[\mathrm{mm}]$} & & 50.4 \\
\hline & Unit linear weight & {$[\mathrm{N} / \mathrm{m}]$} & & 521 \\
\hline & Submerged linear weight & {$[\mathrm{N} / \mathrm{m}]$} & $w$ & 457 \\
\hline & Axial mooring stiffness per unit length $\mathrm{AE}$ & {$[\mathrm{N}]$} & $A E$ & $2.28 \mathrm{E}+0$ \\
\hline & Elasticity of the chain & {$\left[\mathrm{N}^{-1}\right]$} & $f$ & $4.38 \mathrm{E}-0$ \\
\hline
\end{tabular}

Hawser * Wire rope steel capacity 1770 N/mm2

$\begin{array}{cccc}\text { Length } & {[\mathrm{m}]} & & 30 \\ \text { Minimum breaking force } & {[\mathrm{kN}]} & T_{\text {Hmax }} & 2000 \\ \text { Diameter } & {[\mathrm{mm}]} & & 61.7 \\ \text { Unit linear weight } & {[\mathrm{N} / \mathrm{m}]} & & 130 \\ \text { Submerged linear weight } & {[\mathrm{N} / \mathrm{m}]} & & 113 \\ \text { Elasticity of the wire rope } & {\left[\mathrm{N}^{-1}\right]} & f & 4.29 \mathrm{E}-09\end{array}$

Anchor Flipper-Delta anchor in sand

Holding power

Weight

$[\mathrm{kN}]$

$[\mathrm{kN}]$

$T_{\text {Hmax }}$

2000

150

\section{Buoy}

$$
\begin{gathered}
\text { Minimum buoyancy } \\
\text { Unit volume weight buoy } \\
\text { Weight } \\
\text { Volume } \\
\text { Equivalent to a buoy of } \\
\text { height and diameter of }
\end{gathered}
$$

\section{Results}

$$
\begin{aligned}
& \text { Minimum length mooring lines } \\
& \text { Maximum excursion WEC }
\end{aligned}
$$

\section{At Rest}

Horizontal distance anchor to WEC

Tension at end of each line at the WEC at rest

Vertical force at connection with WEC at rest
$[\mathrm{kN}]$

$\left[\mathrm{kN} / \mathrm{m}^{3}\right]$

$[\mathrm{kN}]$

$\left[\mathrm{m}^{3}\right]$

[m]

$[\mathrm{m}]$

[m]

$l_{\min , 0}$

298

1.2

43

35

3.5

$\begin{array}{ccc}{[\mathrm{m}]} & X & 498 \\ {[\mathrm{kN}]} & T & 34 \\ {[\mathrm{kN}]} & T_{z} & 27\end{array}$

[ton]

* The material of the hawser will probably be different, e.g., synthetic, as it is more elastic. The hawser should also be over-dimensioned relative to the chains, if this part is not redundant. 


\subsubsection{Influence of the Pretension}

The influence of the pretension is analysed as it is an independent design variable that can be modified, besides the hawser length. The weight of the mooring lines could also be adapted, but they are in this case dimensioned in accordance with their corresponding design load. The change in pretension has no influence on the length of the mooring lines or the weight of the whole system, as these depends mainly on the horizontal design load at the WEC and water depth, which remained the same (Figure 6). The pretension has almost only an influence on the maximum excursion of the WEC and this only on the part where the restoring force is almost equal to zero. All the related values can be found in Table 6 .

Figure 6. Main results from investigating the influence of the pretension on a spread catenary mooring system.



Table 6. Main results from investigating the influence of the pretension on a CALM system.

\begin{tabular}{cccc}
\hline & Pretension - 50\% & Reference & Pretension + 50\% \\
\hline Pretension $[\mathrm{kN}]$ & 10 & 20 & 30 \\
Max excursion [m] & 17.6 & 14.2 & 12.5 \\
Max $T[\mathrm{kN}]$ & 2014 & 2014 & 2014 \\
Max $T_{H}[\mathrm{kN}]$ & 2000 & 2000 & 2000 \\
Max $T_{z}[\mathrm{kN}]$ & 234 & 234 & 234 \\
Length of the mooring line $l[\mathrm{~m}]$ & 509 & 509 & 509 \\
$X$ at pretension $[\mathrm{m}]$ & 495 & 498 & 500 \\
Nominal diameter of the chain $[\mathrm{mm}]$ & 50.4 & 50.4 & 461 \\
Submerged weight of the chain $[\mathrm{N} / \mathrm{m}]$ & 461 & 301 & 31 \\
Buoy volume $\left[\mathrm{m}^{3}\right]$ & 30 & 3.4 & 3.4 \\
Equivalent to a cylinder of height and diameter $[\mathrm{m}]$ & 3.4 & 114 & 114 \\
Total system weight [ton] & 114 & & \\
\hline
\end{tabular}

The resulting force-displacement curve together with the mooring stiffness curves are given in the next figure (Figure 7). It can be seen that the force-displacement and stiffness curves are just translated to the left or the right depending on the pre-tensioning, while their shape remains the same. The part of 
the curves that is shortened or prolonged is the part of the curves that is almost equal to zero. This should thereby not have a significant influence under a dynamic analysis or situation.

Figure 7. The resulting force-excursion curves and mooring stiffness curves of the spread catenary mooring system for the reference situation (Reference) and the shortening $(-50 \%)$ and extension $(+50 \%)$ of the pretension.

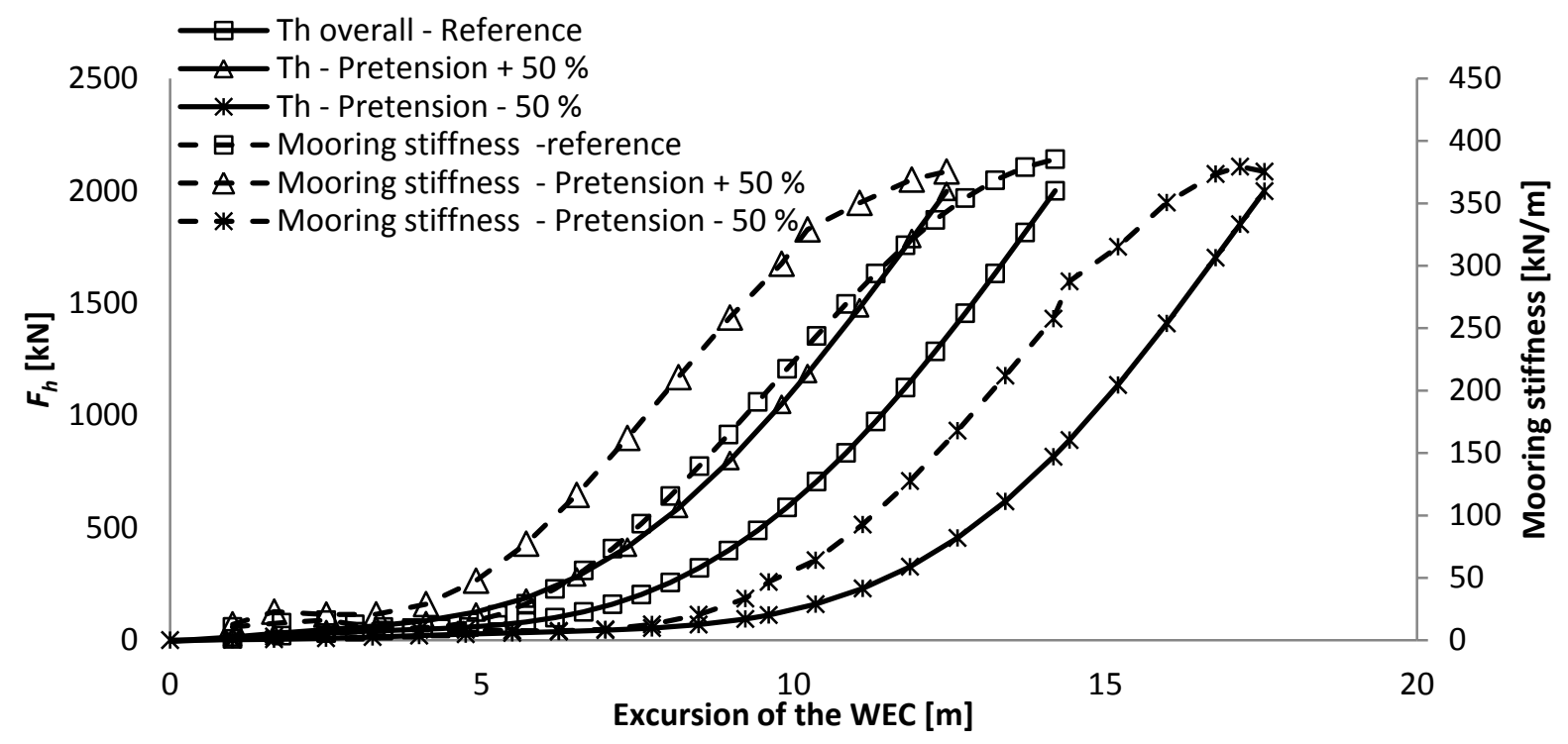

\subsubsection{Influence of the Water Depth}

Keeping the horizontal design load and the hawser length constant, the change in water depth affects the vertical force at the end of the mooring line, which affects the overall tension in the mooring lines and the minimum mooring line length (Figure 8). Although the influence on the maximum tension in the mooring lines is small, the influence on the vertical component $\left(T_{z}\right.$, illustrated in Figure 1) is large and thereby it has a great influence on the minimum length of the mooring line. This influences slightly the chain dimensions, while the anchor holding capacity remains the same (as it is equal to the horizontal design load at the WEC).

Figure 8. Main results from investigating the influence of the water depth on a CALM system.

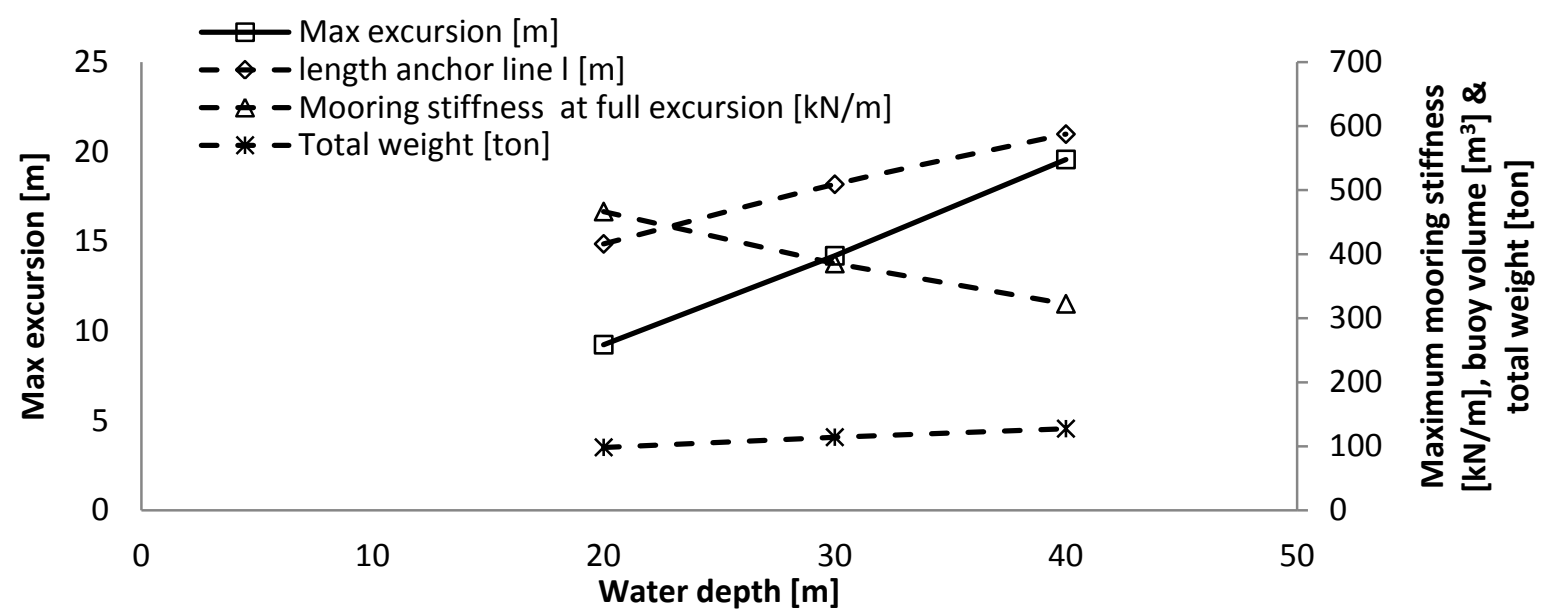


Note that a change in water depth (at a certain location) will change the characteristics of the waves (and especially of the extreme waves), and thereby it is very unlikely that the same WEC would be subjected to the same design loads at different water depths. However, these values intend to present what is to be expected in terms of mooring systems at a different water depth for the same design load.

An increase in water depth of $33 \%$ results in a decrease of the maximum mooring stiffness of $17 \%$, an increase in mooring line length of $15 \%$ and an increase in total system weight of $12 \%$. A decrease of $33 \%$ in water depth corresponds to an increase of the maximum mooring stiffness of $21 \%$, a decrease in mooring line length of $18 \%$ and a decrease in total system weight of $14 \%$. The excursion of the WEC is also strongly influenced by the change in water depth, as it is reduced to $9.2 \mathrm{~m}$ and extended to $19.6 \mathrm{~m}$ from $14.2 \mathrm{~m}$. All the related values can be found in Table 7 .

Table 7. Main results from investigating the influence of water depth on a spread catenary mooring system.

\begin{tabular}{cccc}
\hline & $-\mathbf{3 3 \%}$ Water Depth & Reference & $\mathbf{+ 3 3 \%}$ Water Depth \\
\hline Water depth $[\mathrm{m}]$ & 20 & 30 & 40 \\
Max excursion $[\mathrm{m}]$ & 9.2 & 14.2 & 19.6 \\
Max $T[\mathrm{kN}]$ & 2009 & 2014 & 2018 \\
Max $T_{H}[\mathrm{kN}]$ & 2000 & 2000 & 2000 \\
Max $T_{z}[\mathrm{kN}]$ & 212 & 234 & 310 \\
Length of the mooring line $[[\mathrm{m}]$ & 416 & 509 & 587 \\
$X$ at pretension $[\mathrm{m}]$ & 410 & 498 & 571 \\
Nominal diameter of the chain $[\mathrm{mm}]$ & 50.3 & 50.4 & 50.4 \\
Submerged weight of the chain $[\mathrm{N} / \mathrm{m}]$ & 459 & 461 & 462 \\
Buoy volume $\left[\mathrm{m}^{3}\right]$ & 24 & 30 & 36 \\
Equivalent to a cylinder of height and diameter $[\mathrm{m}]$ & 3.1 & 3.4 & 3.6 \\
Total system weight [ton] & 98 & 114 & 128 \\
\hline
\end{tabular}

The resulting force-displacement curve together with the mooring stiffness curve are given in the next figure (Figure 9). It can be seen that an increase in water depth results in an increase in excursion, partially due to the longer mooring line, and in a lower maximum mooring stiffness making the whole mooring system much more compliant.

\subsubsection{Influence of the Horizontal Design Load at the WEC}

As the minimum breaking force of the chains is set equal to the resultant design load at the WEC, it directly affects also the diameter and the weight of the mooring lines. This will then have an influence on the minimum length of the mooring lines, as it is a function of their weight (Figure 10).

For an increase in horizontal design load at the WEC of $50 \%$, the submerged weight of the chain increases by $58 \%$, the chain length is reduced by $3 \%$, the mooring stiffness at maximum WEC excursion increases by $48 \%$, the maximum WEC excursion increases by only $13 \%$ and the total weight of the system increases by $57 \%$.

While, for a decrease in horizontal design load at the WEC of $50 \%$, the submerged weight of the chain decreases by $58 \%$, the chain length is increased by $9 \%$, the mooring stiffness at maximum WEC 
excursion decreases by $47 \%$, the maximum WEC excursion decreases by $19 \%$ and the total weight of the system increases by $56 \%$. All the related values can be found in Table 8 .

Figure 9. The resulting force-excursion curves and mooring stiffness curves of the spread catenary mooring system for the reference situation (reference, $30 \mathrm{~m}$ ) and the deeper $(+50 \%$ or $40 \mathrm{~m})$ and shallower $(-33 \%$ or $20 \mathrm{~m})$ of water depth.

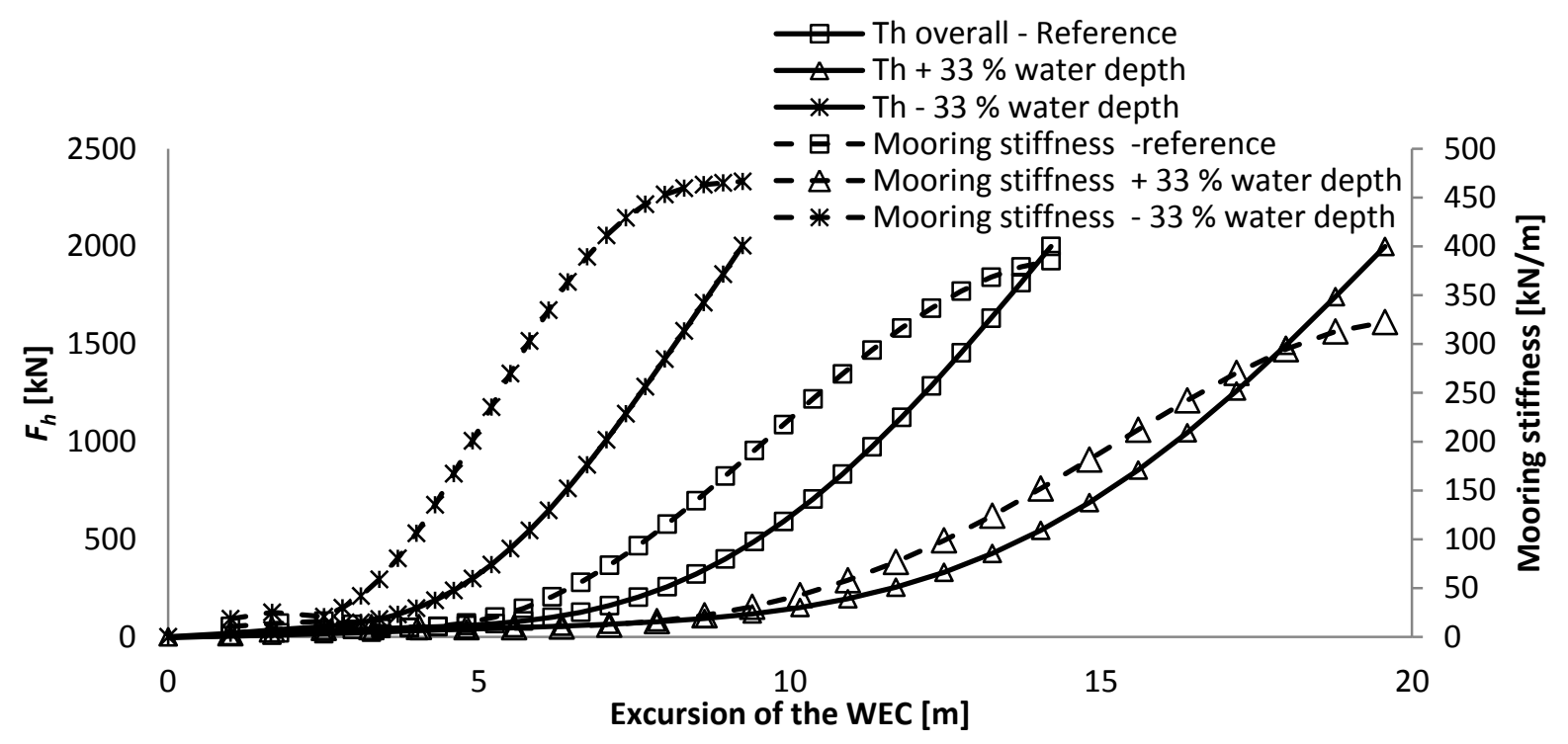

Figure 10. Main results from investigating the influence of horizontal design load at the WEC on a spread catenary mooring system.




Table 8. Main results from investigating the influence of horizontal design load at the WEC on a CALM system.

\begin{tabular}{cccc}
\hline & $\mathbf{- 5 0 \%} \boldsymbol{F}_{\boldsymbol{h} \max }$ & Reference & $\mathbf{+ 5 0 \%} \boldsymbol{F}_{\boldsymbol{h} \max }$ \\
\hline Horizontal design load at the WEC, $F_{h \max }[\mathrm{m}]$ & 1000 & 2000 & 3000 \\
Max excursion $[\mathrm{m}]$ & 11.5 & 14.2 & 16.1 \\
Max $T[\mathrm{kN}]$ & 1006 & 2014 & 3022 \\
$\operatorname{Max} T_{H}[\mathrm{kN}]$ & 1000 & 2000 & 3000 \\
$\operatorname{Max} T_{z}[\mathrm{kN}]$ & 107 & 234 & 361 \\
Length of the mooring line $l[\mathrm{~m}]$ & 557 & 509 & 496 \\
$X$ at pretension $[\mathrm{m}]$ & 550 & 498 & 481 \\
Nominal diameter of the chain $[\mathrm{mm}]$ & 34.5 & 50.4 & 62.8 \\
Submerged weight of the chain $[\mathrm{N} / \mathrm{m}]$ & 192 & 461 & 729 \\
Buoy volume $\left[\mathrm{m}^{3}\right]$ & 14 & 30 & 47 \\
Equivalent to a cylinder of height and diameter $[\mathrm{m}]$ & 2.6 & 3.4 & 3.9 \\
Total system weight [ton] & 50 & 114 & 179 \\
\hline
\end{tabular}

The resulting force-displacement curve together with the mooring stiffness curve are given in the next figure (Figure 11). It can be seen that the maximum mooring stiffness and the maximum excursion of the WEC increase with the horizontal design load at the WEC.

Figure 11. The resulting force-excursion curves and mooring stiffness curves of the CALM system for the reference situation $\left(F_{h} \max =2000 \mathrm{kN}\right)$, a $50 \%$ larger $\left(F_{h \max }=3000 \mathrm{kN}\right)$ and a $50 \%$ lower $\left(F_{h \max }=1000 \mathrm{kN}\right)$ horizontal design load at the WEC.



\subsection{SALM-Sensitivity Investigation}

\subsubsection{Reference Load Case}

When the SALM system is close to be fully extended, the resulting horizontal mooring force starts to increase exponentially with the further excursion of the WEC (which is illustrated by " $F_{H}$ extension" in Figure 3). The resulting mooring force increases so drastically, resulting in an exponential increase of the mooring stiffness, that this part of the force-displacement curve or, in other words, this part of the mooring system cannot be used in practice. Therefore, it was decided to limit the 
admissible maximum extension of the mooring system to up to a maximum angle of 160 degrees between the two mooring lines (tether and hawser). This results in much greater requirements in terms of buoyancy force of the buoy, and it increases significantly the mooring stiffness, relative to if the breaking load of the system was set to $2000 \mathrm{kN}$, just as for the CALM system.

In the figure (Figure 3), the force displacement curve is given together with the mooring stiffness curve, against the excursion of the WEC and against the relative angle between the tether and hawser.

Limiting the maximum angle between the hawser and tether limits also the maximum stiffness of the system. Up to this imposed maximum angle, the force-displacement curve increases almost linearly, while the mooring stiffness already begins to increase exponentially half way through the curve. All the related values and details of the mooring configuration can be found in Table 9 .

Table 9. Summary of the main details of the SALM system for the reference load case.

\begin{tabular}{|c|c|c|c|c|}
\hline Sub-System & & Unit & Symbol & Value \\
\hline \multicolumn{5}{|l|}{ Buoy } \\
\hline & Depth of the buoy at rest & {$[\mathrm{m}]$} & $z_{\text {rest }}$ & 8.5 \\
\hline & Minimum buoyancy & {$[\mathrm{kN}]$} & $F_{\text {buoy }}$ & 2178 \\
\hline & Unit volume weight buoy & {$\left[\mathrm{kN} / \mathrm{m}^{3}\right]$} & & 1.2 \\
\hline & Weight & {$[\mathrm{kN}]$} & & 304 \\
\hline & Volume & {$\left[\mathrm{m}^{3}\right]$} & & 247.6 \\
\hline & $\begin{array}{l}\text { Equivalent to a cylinder of } \\
\text { equal height and diameter }\end{array}$ & {$[\mathrm{m}]$} & & 6.8 \\
\hline \multirow[t]{7}{*}{ Tether } & Wire rope steel capacity $1770 \mathrm{~N} / \mathrm{mm}^{2}$ & & & \\
\hline & Length & {$[\mathrm{m}]$} & $l_{l, 0}$ & 20.5 \\
\hline & Minimum breaking force & {$[\mathrm{kN}]$} & $T_{\operatorname{lmax}}$ & 2957 \\
\hline & Diameter & {$[\mathrm{mm}]$} & & 68 \\
\hline & Unit linear weight & {$[\mathrm{N} / \mathrm{m}]$} & & 193 \\
\hline & Submerged linear weight & {$[\mathrm{N} / \mathrm{m}]$} & & 168 \\
\hline & Elasticity of the wire rope & {$\left[\mathrm{N}^{-1}\right]$} & $f$ & $4.1 \mathrm{E}-09$ \\
\hline \multirow[t]{7}{*}{ Hawser } & Wire rope steel capacity $1770 \mathrm{~N} / \mathrm{mm}^{2}$ & & & \\
\hline & Length & {$[\mathrm{m}]$} & $l_{2,0}$ & 30 \\
\hline & Minimum breaking force & {$[\mathrm{kN}]$} & $T_{2 \max }$ & 2254 \\
\hline & Diameter & {$[\mathrm{mm}]$} & & 59 \\
\hline & Unit linear weight & {$[\mathrm{N} / \mathrm{m}]$} & & 147 \\
\hline & Submerged linear weight & {$[\mathrm{N} / \mathrm{m}]$} & & 127 \\
\hline & Elasticity of the wire rope & {$\left[\mathrm{N}^{-1}\right]$} & $f$ & $4.2 \mathrm{E}-09$ \\
\hline \multirow[t]{7}{*}{ Anchor } & Suction anchor in medium soft clay & & & \\
\hline & Diameter & {$[\mathrm{m}]$} & & 3.8 \\
\hline & height & {$[\mathrm{m}]$} & & 7.6 \\
\hline & Lid thickness & {$[\mathrm{mm}]$} & & 100 \\
\hline & wall thickness & {$[\mathrm{mm}]$} & & 26 \\
\hline & Weight & [ton] & & 27 \\
\hline & Total mooring system weight & [ton] & & 59 \\
\hline
\end{tabular}




\subsubsection{Influence of the Length of the Hawser}

The main design variable that, in this case, can be adapted is the length of the hawser, as the length of the tether is a function of the water depth, and the volume of the buoy is calculated to fulfill the mooring requirements. The length of the hawser is however inversely proportional to the required buoyancy force, as a longer hawser demands a smaller buoy in order to maintain a similar compliant mooring system (Figure 12). The influence of the length of the hawser has here been assessed by modifying it by $33 \%$ around the original $30 \mathrm{~m}$ length. The characteristics of the reference load situation, horizontal design load at a WEC of $2000 \mathrm{kN}$ and at $30 \mathrm{~m}$ of water depth, has been maintained.

Figure 12. Main results from investigating the influence of the (unstretched) length of the hawser, $l_{2,0}$, of the SALM system.

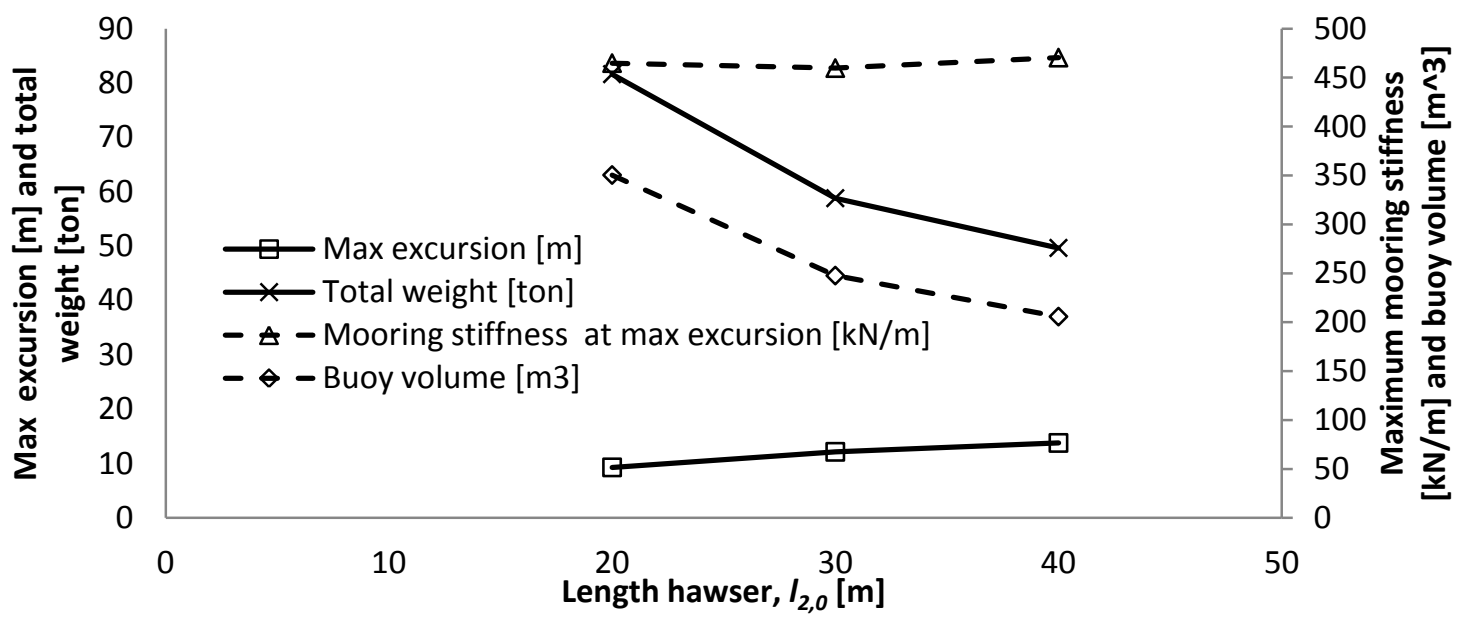

So, if the length of the hawser is increased by $33 \%$, the required buoyancy force of the buoy drops (by $17 \%$ ), which results in a lower maximum tension in the tether $T_{1}$ and hawser $T_{2}$ (decrease of $9 \%$ and $4 \%$ ), while the maximum excursion increases (13\%). As the maximum tension in the tether decreases slightly, the dimensions of the suction anchor also decreases, and the same results for the overall weight of the system (reduction of $16 \%$ ). However, if the length of the hawser gets shortened (by 33\%) then the opposite is true and the weight of the whole installation increases (by 39\%). All the related values can be found in Table 2 .

The resulting force-displacement curve together with the mooring stiffness curve is given in the next figure (Figure 13). The increase in hawser length increases especially the compliance and the maximum excursion of the WEC, while the maximum mooring stiffness remains approximately the same. This is quite surprising, as the volume of the buoy has changed significantly.

\subsubsection{Influence of the Water Depth}

An increase in water depth leads to an increase in length of the tether $l_{l}$, while the horizontal design load at the WEC and the length of the hawser remains the same.

Note that a change in water depth (at a certain location) will change the characteristics of the waves (and especially of the extreme waves), and thereby it is very unlikely that the same WEC would be 
subjected to the same design loads at different water depths. However, these values intend to present what is to be expected in terms of mooring systems at different water depths for the same design load.

Figure 13. The resulting force-excursion curves and mooring stiffness curves of the SALM system for the reference situation (reference) and the shortening $(-50 \%)$ and extension $(+50 \%)$ of the hawser, $l_{2}$.

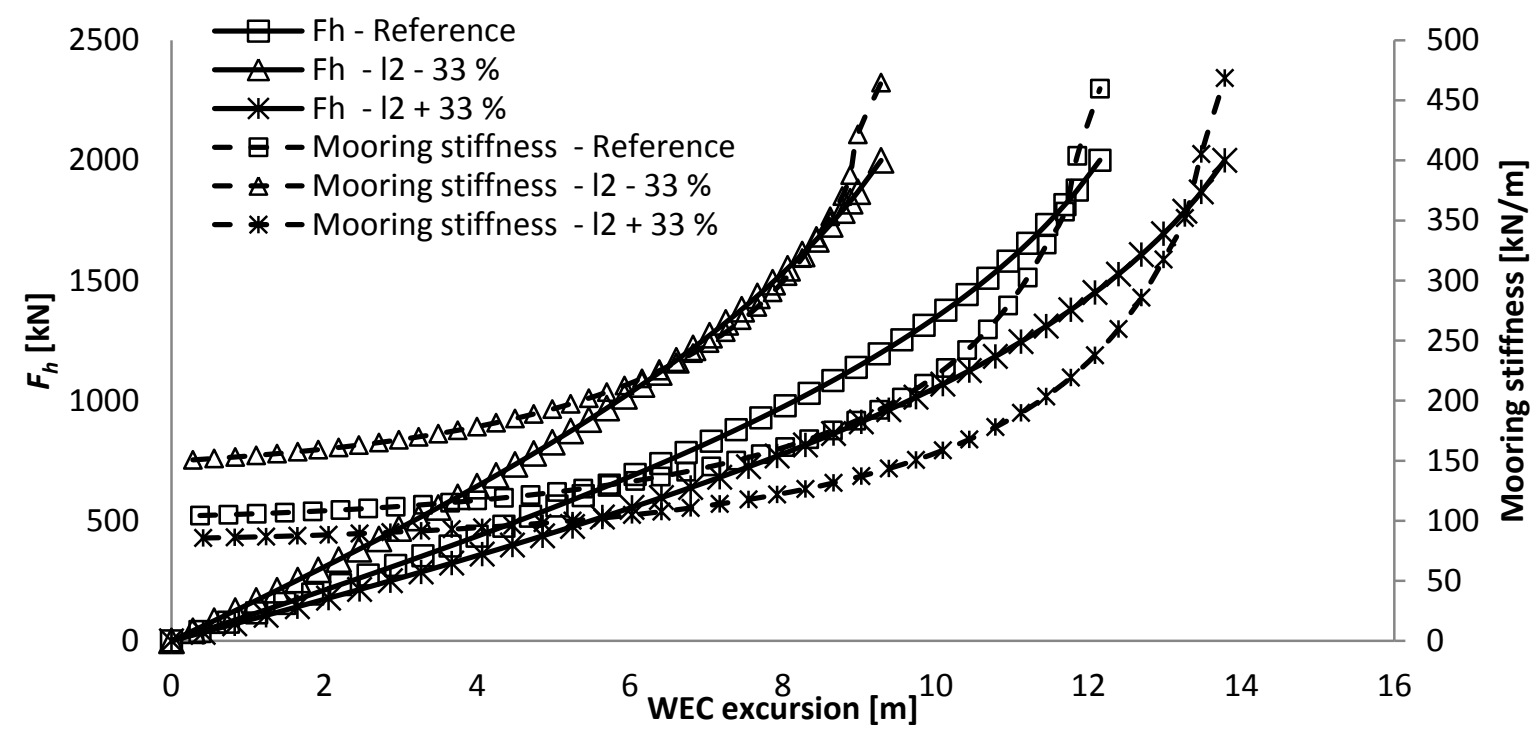

An increase in water depth (33\%), and thereby an increase in tether length (48\%), affects mainly the maximum excursion of the WEC $(+37 \%)$ and reduces significantly the maximum mooring stiffness (by $32 \%$ ) (Figure 14). However, the volume of the buoy increases slightly (by 13\%) and as does the weight of the whole system (12\%). For a reduction in water depth of $33 \%$, the same but opposite values are almost applicable, except that the maximum mooring stiffness increases by $91 \%$ and the maximum excursion get reduced by $42 \%$. All the values can be found in Table 3 .

Figure 14. Main results from investigating the influence of the water depth on a SALM system.

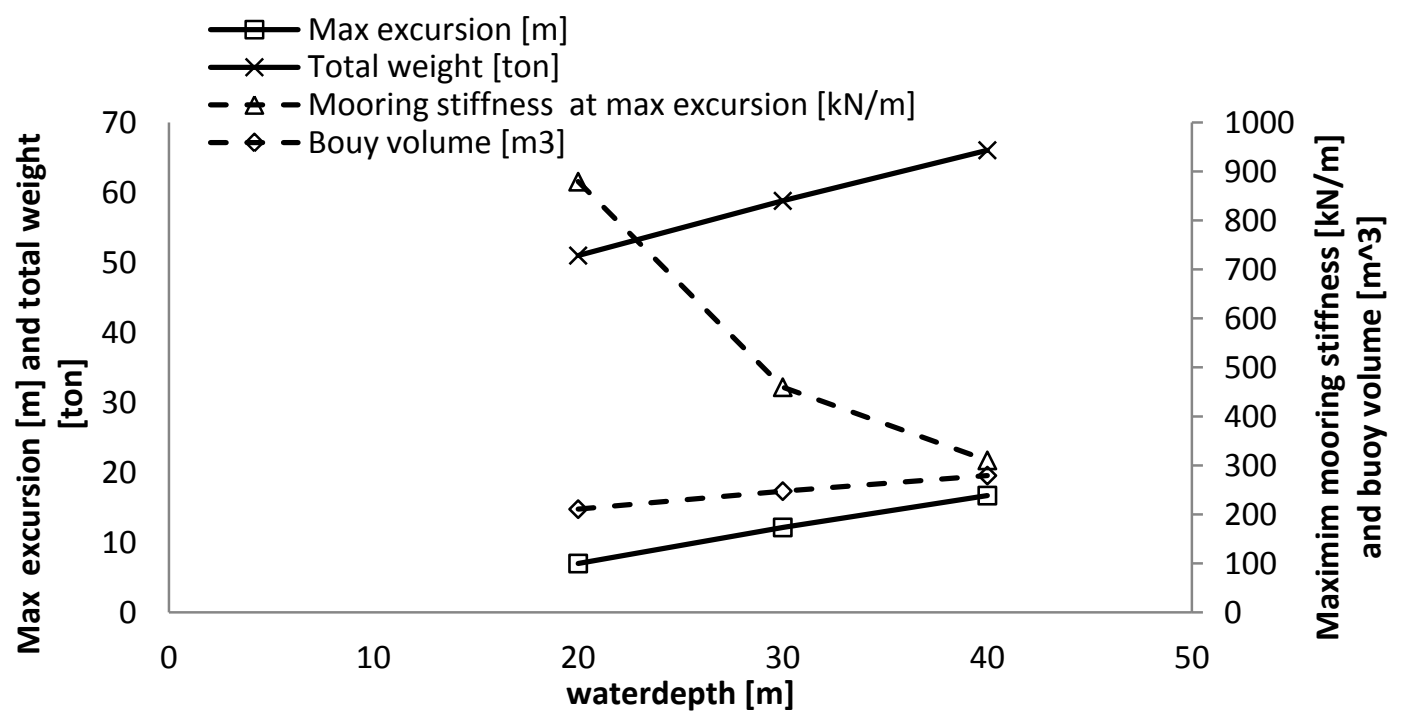


The resulting force-displacement curve together with the mooring stiffness curve are given in the next figure (Figure 15). With an increase in water depth, the main changes are the increase in maximum WEC excursion and especially the reduction in the maximum mooring stiffness.

Figure 15. The resulting force-displacement curves and mooring stiffness curves of the SALM system for the reference situation (reference, $30 \mathrm{~m})$ and the increased $(+50 \%$ or $40 \mathrm{~m})$ and reduced $(-50 \%$ or $30 \mathrm{~m})$ water depth.

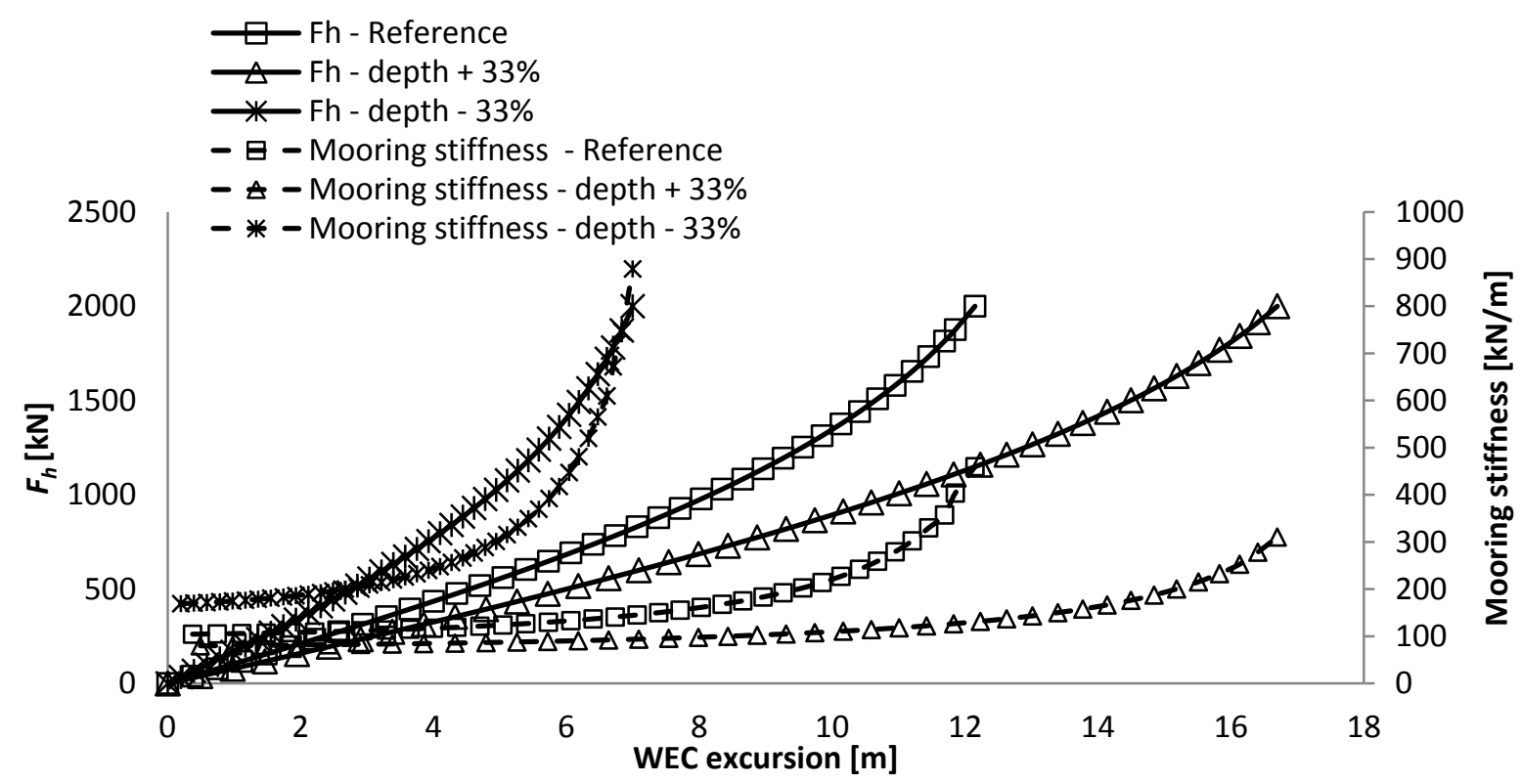

\subsubsection{Influence of the Horizontal Design Load at the WEC}

While the horizontal design load at the WEC has been changed, the water depth and the length of the hawser have been kept the same. This change in load was countered by an adjustment of the volume of the buoy, which affects slightly the length of the tether and thereby also the maximum excursion of the WEC (Figure 16). This means that a higher horizontal mooring design load at the WEC will result in a higher maximum mooring stiffness of the system, as the force is significantly increased while the excursion is slightly reduced.

As the maximum tension in the lines change according to the horizontal design load at the WEC, the dimensions of the suction anchor change as well, having a significant influence on the system weight $(+57 \%$ and $-53 \%$ for a variation of the horizontal design load at the WEC of $+/-50 \%)$. All the values can be found in Table 4.

The resulting force-displacement curve together with the mooring stiffness curve are given in the next figure (Figure 17). It is mainly the maximum mooring stiffness that increases due to the increase in buoy volume, as the maximum excursion remains almost the same (the length of the tether is slightly reduced due to the increased volume of the buoy).

These outcomes are a bit controversial, as less compliant systems (having a higher mooring stiffness) will result in a higher horizontal design load and vice-versa. This results in an undesirable situation, something similar to a vicious circle. Thereby, the selection of the volume of the buoy is of great importance and has to be assessed dynamically. 
Figure 16. Main results from investigating the influence of horizontal design load at the WEC on a SALM system.

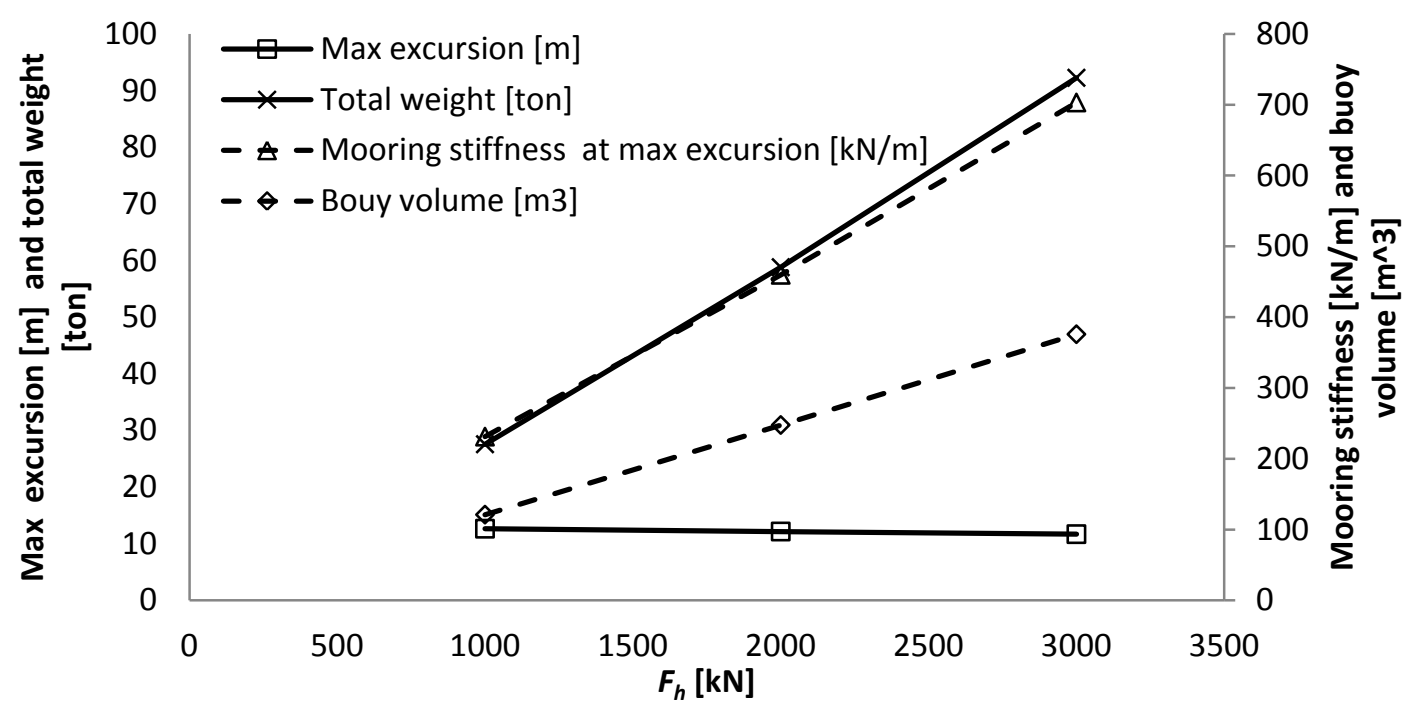

Figure 17. The resulting force- excursion curves and mooring stiffness curves of the SALM system for the reference situation (reference, $2000 \mathrm{kN})$ and the increased $(+50 \%$ or $3000 \mathrm{kN})$ and reduced $(-50 \%$ or $1000 \mathrm{kN})$ horizontal design load at the WEC.

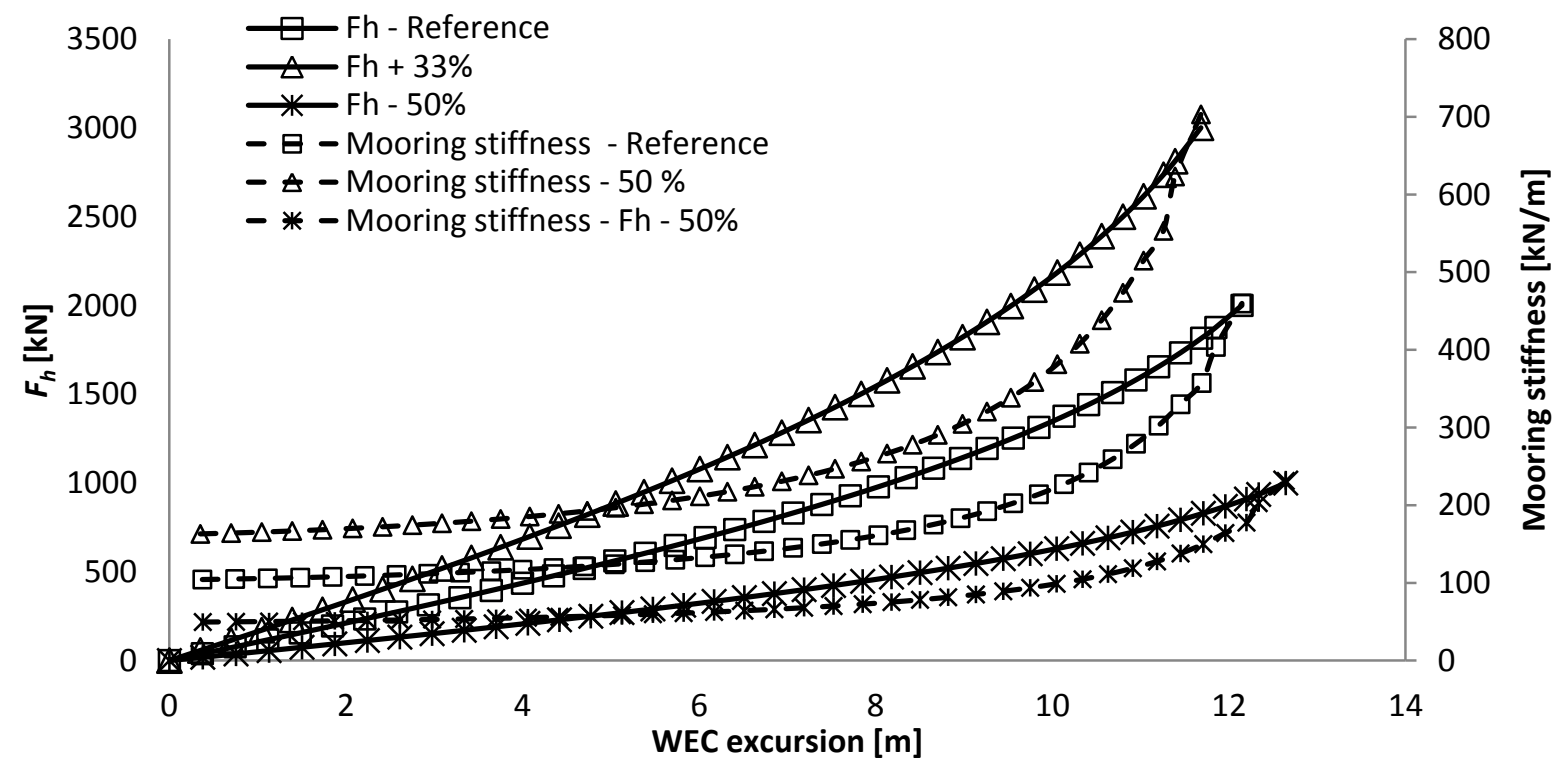

\subsection{Comparison between the CALM and SALM System}

\subsubsection{Reference Load Case}

The two mooring configurations present very different force-displacement and mooring stiffness curves under the identical reference load case, as can be seen in the following figure (Figure 18). Although the CALM system allows a larger excursion of the WEC (up to $14.2 \mathrm{~m}$ relative to $12.1 \mathrm{~m}$ for the SALM), it has almost no restoring force or mooring stiffness over the first $5 \mathrm{~m}$. The SALM has an almost linear increase in horizontal mooring force relative to the excursion up to approximately $75 \%$ of 
the maximum excursion, where it then begins to increase more rapidly. This is easily seen in the mooring stiffness curve as this represents the local steepness of the force-displacement curve. For the CALM system, both curves remain close to zero up to approximately $5 \mathrm{~m}$ of WEC excursion, meaning that there is almost no restoring force up to this point, where it than starts to increase exponentially up to approximately $11.5 \mathrm{~m}$, where it then continues to increase linearly. At maximum WEC excursion, the CALM system has a maximum mooring stiffness of $387 \mathrm{kN} / \mathrm{m}$ while it is $460 \mathrm{kN} / \mathrm{m}$ for the SALM system.

Figure 18. The resulting force- displacement and mooring stiffness curve for the CALM and SALM systems dimensioned for the same quasi-static load $(2000 \mathrm{kN})$ and water depth $(30 \mathrm{~m})$.



Based on these curves, it is difficult to say, which mooring system is the most suitable or will actually result in the lowest mooring loads. A dynamical or experimental analysis should give a much better view on this.

\subsubsection{Influence of the Water Depth}

The SALM system is the most sensitive to the change in water depth, as an increase in water depth $(+33 \%)$ has a large effect on the maximum mooring stiffness of the SALM system $(-32 \%)$, which can be seen in the following figure (Figure 19). A decent but smaller positive effect on the CALM system $(-17 \%)$ can also be seen. The opposite trend is also true, where the maximum mooring stiffness increases by as much as $91 \%$ for the SALM system but only $21 \%$ for the CALM system, when the water depth is reduced by $33 \%$ to $20 \mathrm{~m}$.

At a water depth of $40 \mathrm{~m}$, both systems present approximately a similar maximum mooring stiffness (310 and $322 \mathrm{kN} / \mathrm{m}$ for the SALM and CALM), but the SALM system is much lighter than the CALM system (60 against 128 ton). 
Figure 19. Comparison of the maximum mooring stiffness and weight of the CALM and SALM systems for different water depths.

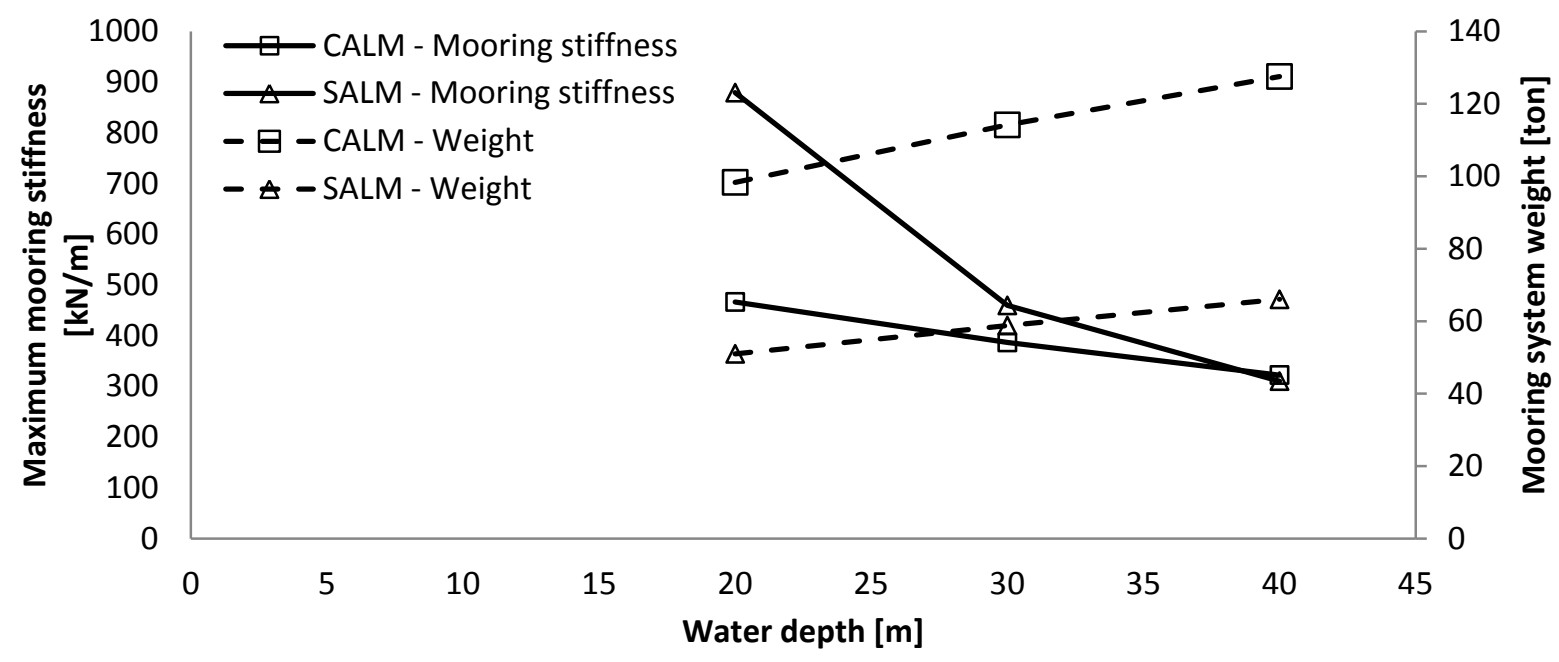

The next figure (Figure 20) presents the force-displacement and mooring stiffness curves for the CALM and SALM system at a water depth of $40 \mathrm{~m}$, where both systems present a similar maximum mooring stiffness.

Figure 20. Presentation of the resulting force-displacement and mooring stiffness curve for the CALM and SALM systems dimensioned for the same quasi-static horizontal design load at the WEC $(2000 \mathrm{kN})$ and $40 \mathrm{~m}$ of water depth.

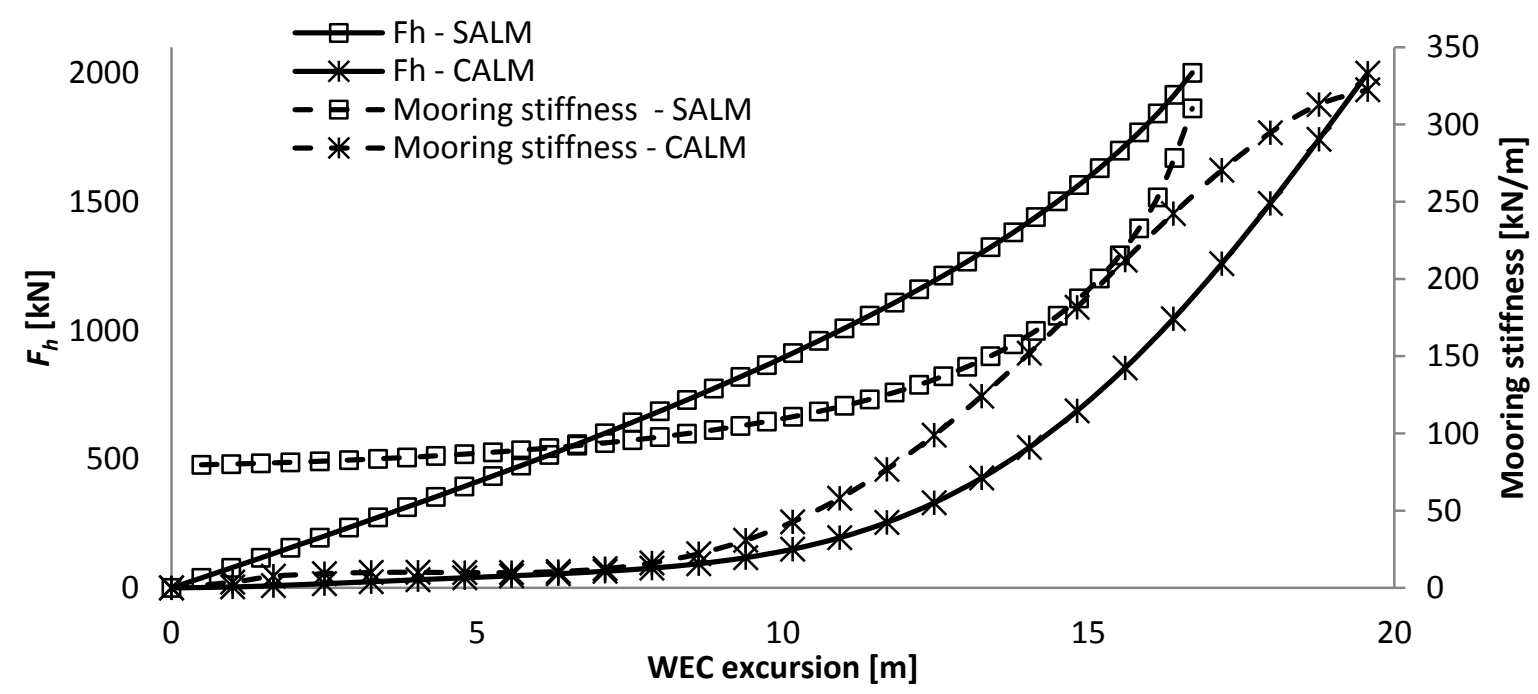

Note that although the CALM system appears to allow greater maximum WEC excursions, the force-displacement and mooring stiffness curve remain close to zero up to an excursion of the WEC of approximately $7 \mathrm{~m}$.

\subsubsection{Influence of the Horizontal Design Load at the WEC}

For the SALM system, the increase in horizontal design load at the WEC $(+50 \%)$ is mainly countered by an increase in buoy volume $(+52 \%)$, while for the CALM system this is done by 
increasing the weight of the chains $(+58 \%)$, which can be seen in the following figure (Figure 21$)$. For both systems, this results in an increase in maximum mooring stiffness $(+53 \%$ and $+48 \%)$ and an increase in the total weight of the system $(+59 \%$ and $+57 \%$ for the SALM and CALM system, respectively).

Figure 21. Comparison of the maximum mooring stiffness and weight of the CALM and SALM systems for different horizontal design loads.



The next figure (Figure 22) presents the force-displacement and mooring stiffness curves for the CALM and SALM system for a horizontal design load of $3000 \mathrm{kN}$. In this case, the maximum mooring stiffness is larger for the SALM system, while the maximum excursion for the WEC is larger for the CALM mooring.

Figure 22. Presentation of the resulting force- displacement and mooring stiffness curve for the CALM and SALM systems dimensioned for the same quasi-static horizontal design load at the WEC of $3000 \mathrm{kN}$ and $30 \mathrm{~m}$ of water depth.

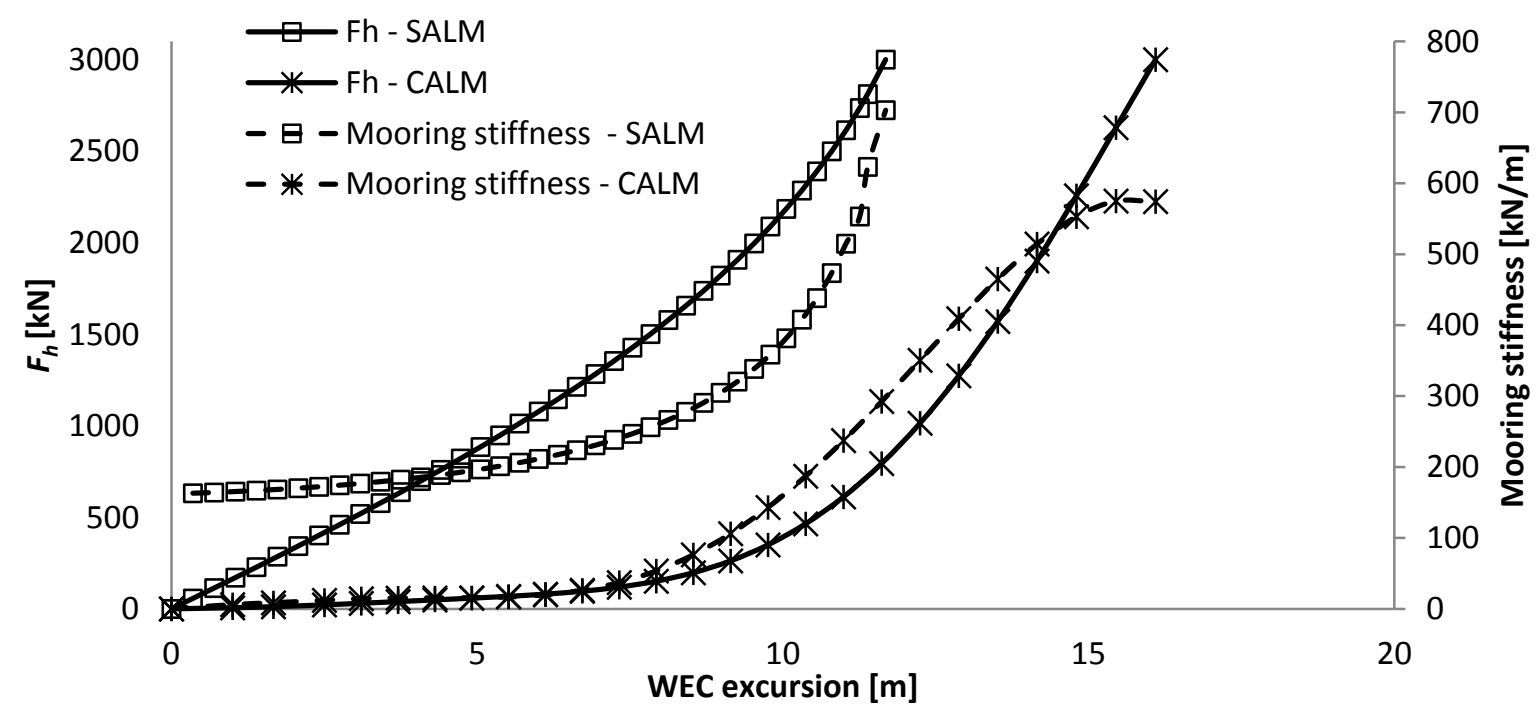

Note again that although the CALM system appears to allow greater maximum WEC excursions, the force-displacement and mooring stiffness curve remain close to zero up to an excursion of the 
WEC of approximately $6 \mathrm{~m}$. Without this $6 \mathrm{~m}$, which could be avoided by increasing the pretension, the maximum excursion of the WEC for both mooring systems would be approximately the same.

\section{Observations and Conclusions}

Quasi-static analyses on two different types of mooring systems have been performed for a reference load case and for three other cases, where an important environmental or design parameter has been modified. The mooring systems are a three-legged catenary anchor leg mooring (CALM) system and a single anchor leg mooring (SALM) system, also referred to as a tension leg mooring system. The reference case corresponds to a horizontal design load at the WEC of $2000 \mathrm{kN}$ and a water depth of $30 \mathrm{~m}$. Around this reference case, the influence of a main mooring design parameter was investigated, as well as the influence of the water depth and of the horizontal design load at the WEC on the design of the mooring systems.

The main observations for the CALM system are:

- The reference case consists of chains that are each $509 \mathrm{~m}$ long and have a diameter of $50 \mathrm{~mm}$, the maximum excursion of the WEC is $14.2 \mathrm{~m}$ and the total weight of the system is 132 ton.

- The force-displacement curve remains very low up to half the excursion, as at an excursion of $7.0 \mathrm{~m}$ the resulting horizontal mooring force is still only of $178 \mathrm{kN}$, where it then starts to increase exponentially.

- The pre-tension influences mainly the maximum excursion of the system, but not the mooring stiffness, as the force-displacement curve has the same shape and inclination, but is just translated. It might thereby not have an influence on the dynamic response of the system.

- For greater water depths, the length of the same mooring lines needs to be increased, resulting in a larger maximum excursion of the WEC and a lower maximum mooring stiffness.

- For larger horizontal mooring forces, the submerged weight and dimension of the chains need to be significantly increased; while their required length remains roughly the same. This results in an increase in maximum WEC excursion and maximum mooring stiffness.

The main observations of the SALM system are:

- As the system is always under tension, the mooring stiffness is present from the smallest WEC excursion. The mooring stiffness increases almost linearly with the excursion of the WEC up to about $80 \%$ of the maximum excursion of the WEC $(12.1 \mathrm{~m})$, and then it increases exponentially. The total weight of the system is 60 ton.

- The length of the hawser has a significant influence on the maximum excursion of the WEC, while it does not affect the mooring stiffness as the volume of the buoy changes inversely.

- In this quasi-static analysis, the length of the tether was set in relationship with the water depth. A larger water depth mainly decreases the maximum mooring stiffness, while it increases slightly the volume of the buoy and the maximum excursion of the WEC.

- The increase in horizontal design load is, in this case, compensated directly by an increase in the volume of the buoy. This influences the maximum mooring stiffness of the system and reduces slightly the maximum excursion of the WEC due to the increased size of the buoy and thereby reduction in length of the tether. 
Both systems appear to have advantages and inconveniences. Some comparison can be made:

- For the reference situation, the maximum mooring stiffness coming from this quasi-static analysis is larger for the SALM system. However, it is not sure that this would also result from a dynamic or experimental analysis, due to the slack initial distance of the CALM system.

- The maximum mooring stiffness resulting from this quasi-static analysis is approximately the same for both mooring systems at a water depth of about $40 \mathrm{~m}$.

- The footprint of the SALM system is much more compact and light (60 ton), as it only requires the suction anchor on the seabed. The CALM system has a very large footprint as it is composed of three mooring lines of approximately $500 \mathrm{~m}$ and three anchors, so it is much heavier (up to 132 ton).

- The CALM system presents more redundancy, as it is composed of three mooring lines, which each should be able to take the full mooring load. This of course requires the hawser to be stronger than the chains and possibly doubled to have full redundancy on the system. The SALM system does not present any obvious redundancy, unless the whole system would be doubled. In case no redundancy is provided, the system requires an additional safety factor (multiplication factor of 1.2).

- The mooring stiffness increases very differently with the excursion of the WEC for both systems. The catenary mooring has a very low mooring stiffness of up to about $50 \%$ of its excursion after which it increase very steeply. The SALM system has a much more progressive mooring stiffness as it increases linearly up to $80 \%$ of its excursion, after which it increases steeply. So, it appears that the operational working range of the SALM mooring is greater than for the CALM system and this will have a very strong influence on the dynamic behaviour of the system and the resulting mooring loads.

\section{Acknowledgments}

The authors gratefully acknowledge the financial support from the Danish Council for Strategic Research under the Programme Commission on Sustainable Energy and Environment (Contract 09-067257; Structural Design of Wave Energy Devices) and the ForskEL R\&D programme administered by energinet.dk (Contracts 2013-1-12057; Common prestudy and tests of wave power challenges; and 2013-1-12039; Weptos WEC Hanstholm) which made this work possible.

\section{Conflicts of Interest}

The authors declare no conflict of interest.

\section{References}

1. Ocean Energy Systems OES Annual Report 2012: Implementing Agreement on Ocean Energy Systems; The Executive Committee of Ocean Energy Systems: Lisbon, Portugal, 2012.

2. Offshore Standard DNV-OS-E301: Position Mooring; Det Norske Veritas: Høvik, Norway, 2010.

3. Johanning, L.; Smith, G.H.; Wolfram, J. Mooring design approach for wave energy converters. J. Eng. Marit. Environ. 2006, 220, 159-174. 
4. Kirrane, P.; Fabricius, P.; Morvan, R. Development of an Efficient Design Technique for the Optimisation of Mooring Systems for Wave Energy Arrays; Marine Insitute: Galway, Ireland, 2011.

5. Harris, R.E.; Johanning, L.; Wolfram, J. Mooring Systems for Wave Energy Converters: A Review of Design Issues and Choices. In Proceedings of 3rd International Conference on Marine Renewable Energy, Edinburgh, UK, 7-9 July 2004.

6. Guidelines on Design and Operation of Wave Energy Converters; Det Norske Veritas: Høvik, Norway, 2005.

7. Synodis, S.T.; Flory, J.F. Six Years Experience with the BREGA Single Anchor Leg Mooring. In Proceeding of Offshore Technology Conference, Houston, TX, USA, 2-5 May 1977.

8. Faltinsen, O.M. Sea Loads on Ships and Offshore Structures; Cambridge University Press: Cambridge, UK, 1990.

9. Design of Ocean Systems. Available online: http://ocw.mit.edu/courses/mechanical-engineering/ 2-019-design-of-ocean-systems-spring-2011 (accessed on 1 November 2013).

10. Pecher, A.; Kofoed, J.P.; Larsen, T. Design Specifications for the Hanstholm WEPTOS Wave Energy Converter. Energies 2012, 5, 1001-1017.

11. Parmeggiani, S.; Kofoed, J.; Friis-Madsen, E. Experimental Study Related to the Mooring Design for the 1.5 MW Wave Dragon WEC Demonstrator at DanWEC. Energies 2013, 6, 1863-1886.

12. Lecture Notes for the Course in Water Wave Mechanics. Available online: http://vbn.aau.dk/da/ publications/lecture-notes-for-the-course-in-water-wave-mechanics(69731932-7a17-47ea-b557-6 b9e0c81050f).html (accessed on 1 November 2013).

13. Wavelab 3-Data acquisition and Analysis Software. Available online: http://www.hydrosoft. civil.aau.dk/wavelab/ (accessed on 1 December 2013).

14. Le Tirant, P.; Meunier, J. Design Guides for Offshore Structures; Editions Technip: Rueil-Malmaison, France, 1990.

15. Andersen, K.H.; Murff, J.D.; Randolph, M.F.; Clukey, E.C.; Erbrich, C.T.; Jostad, H.P.; Hansen, B.; Aubeny, C.; Sharma, P.; Supachawarote, C. Suction Anchors for Deepwater Applications. In Proceedings of the International Symposium on Frontiers in Offshore Geotechnics (IS-FOG 2005), Perth, Australia, 19-21 September 2005; doi:10.1201/NOE0415390637.ch1.

16. Randolph, M.F.; Gourvenec, S. Offshore Geotechnical Engineering; CRC Press: Boca Raton, FL, USA, 2011; p. 550.

17. Supachawarote, C.; Randolph, M.F.; Gourvenec, S. Inclined Pull-Out Capacity of Suction Caissons. In Proceedings of 14th International Offshore and Polar Engineering Conference, Perth, Australia, 23-28 May 2004; p. 500.

(C) 2014 by the authors; licensee MDPI, Basel, Switzerland. This article is an open access article distributed under the terms and conditions of the Creative Commons Attribution license (http://creativecommons.org/licenses/by/3.0/). 